AECU-3594

Report No..

\title{
Technical Progress Report on
}

\section{RESEARCH AND INVESTIGATION LEADING TO METHODS OF GENERATING AND DETECTING RADIATION IN THE 100 TO 1000 MICRON RANGE OF THE SPECTRUM}

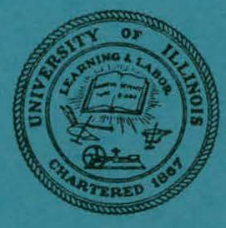

ULTRAMICROWAVE SECTION

ELECTRICAL ENGINEERING RESEARCH LABORATORY ENGINEERING EXPERIMENT STATION UNIVERSITY OF ILLINOIS URBANA, ILLINOIS 


\section{DISCLAIMER}

This report was prepared as an account of work sponsored by an agency of the United States Government. Neither the United States Government nor any agency Thereof, nor any of their employees, makes any warranty, express or implied, or assumes any legal liability or responsibility for the accuracy, completeness, or usefulness of any information, apparatus, product, or process disclosed, or represents that its use would not infringe privately owned rights. Reference herein to any specific commercial product, process, or service by trade name, trademark, manufacturer, or otherwise does not necessarily constitute or imply its endorsement, recommendation, or favoring by the United States Government or any agency thereof. The views and opinions of authors expressed herein do not necessarily state or reflect those of the United States Government or any agency thereof. 


\section{DISCLAIMER}

Portions of this document may be illegible in electronic image products. Images are produced from the best available original document. 
TECHNICAL PROGRESS REPORT NO。 2

on

RESEARCH AND INVESTIGATION

LEADING TO METHODS OF

GENERATING AND DETECTING

RADIATION IN THE

100 TO 1000 MICRON WAVELENGTH

RANGE OF THE SPECTRUM

Contract No. AT (11-1)-392

Quarterly Report No. 6

by

$P_{i}$ D. Coleman

M.D. Sirkis

R.C. Becker

R.J. Kenyon

H.A. Spuhler

A.W. Swago

Period Covered:

Date:

1 June 1957

to

1 September 1957

Supported by

UNITED STATES ATOMIC ENERGY COMMISSION

Ultramicrowave section

Electrical Engineering Research Laboratory

Engineering Experiment Station

University of Illinois

Urbana, Ilzinois 
CONTENTS

1. Introduction

Page

1.1 Preface

1.2 Purpose

2. General Factual Data

2.1 Approach to the Generation Problem--Frequency Multiplication with Non-Linear Element

2.2 Bunched Megavolt Beams as Non-Linear Elements for Use in Megavolt Flectronics

2.3 Megavolt Coupling :Structure Research 5

2.4 Detectors and Components.

2.5 Present Status of the Work 1

2.5.1 Rebatron Research 8

2.5.2 Beam Coupling Schemes 9

2.5.3 Detecting and Measuring Techniques 9

2.6 Personne1 9 9

2.7 Papers, Reports, Publications, Visits $\quad 10$

3. Detailed Factual Data 12

3.1 Rebatron 12

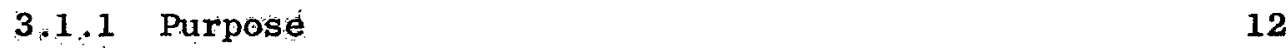

3.1.2 Electron Injection Problem 12

3.1.3 Rebatron Design above $3 \mathrm{kmc} / \mathrm{s} \quad 14$



3.2 Beam Coupling Schemes 24

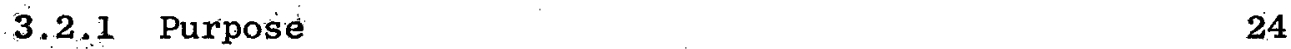

3.2.2 The Slow-Wave Dieloctric Harmodotron 24

3.3 Detecting and Measuring Techniques 41

3.3.1 Purpese 41

3.3.2 Millimeter Wave Tèchniques 41

Distribution List 


\section{ILLUSTRATIONS}

Figure

Number

Page

1. Megavolt Electronics System. 3

2. Rebatron Structure 4

3. $\mathrm{X}$-Band Bunching Accelerator 5

4. Excitation of $\mathrm{TM}_{\text {omn }}$ Modes of Cylindrical Metal Cavity 5

5. Dielectric Harmodotron 6

6. Cerenkov Radiator 7 .

7. Present $S-B a n d$ Rebatron 13

8. New Portable S-Band Rebatron under Construction 13

9. New S-Band Rebatron Cavity with Removable End Wall for Attaching Coupling Structure Directly to Exit Beam Hole 16

10. Crystal Multipliers with Two and One Milimeter Components 16

11. Coupling Hole Measurements. 17

12. Coupling Hole Measurement No. 1 . 18

13. Coupling Hole Measurement No: 2

14. Coupling Hole Measurement No. $3 \quad 20$

15. Reference Plane Measurements 21

16. Reference Planes 22

17. Tee for Removabie Wall Accelerating Cavity 23

18. Slow-Wave Dielectric Harmodotron 25

19. Submillimeter Cavity 27

20. Slow-Wave Dielectric Harmodotron Assembly for Submilimeter Waves

21. Cutoff Wavelengths for Modes of Propagation in the Output Waveguide of the Submillimeter Slow-Wave Dielectric Harmodotron

22. TM Modes for $a / b=0.8$

23. TM Modes for $\mathrm{a} / \mathrm{b}=0.5$

24. TM Modes for $a, b=0.2$

25. Theoretical Power Curves for the Slow-Wave Dielectric Harmodotron for $\lambda_{0}=9 \mathrm{~mm}$. 40

26, Overail System 42 


\section{INTRODUCTION - P.D.COL}

\subsection{Preface}

This is the combined second technical progress report and sixth quarterly report for Contract No. AT(11-1)-392 on "Research and Investigation Leading to Methods of Generating and Detecting Radiation in the 100 to 1000 Micron Wavelength Range of the spectrum This report covers the period 1 June 1957 to 1 September 1957.

\subsection{Purpose}

The purpose of this research is twofold:

a) To uncover new principles or techniques from which a source of high pulsed power for the 100-1000 micron wavelength range of

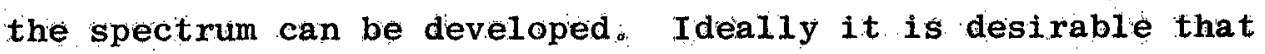
the source w111 possess a line spectrum.

b) To investigate suitable detecting and measuring techniques for evaluating and using the radiation as a diagnostic tool for physical research. 
2. GENERAL FACTUAL DATA $-\mathrm{P} . \mathrm{D}$. Coleman

2.1 Approach to the Generation Problem--Frequency Multiplication with NonLinear Element

The generation of electromagnetic radiation in the wavelength range 0.1 to 3 millimeters is as yet an unsolved problem. Electron tubes, which represent a very desirable source in that they are compact, coherent, tunable, line spectrum oscillators, have been extended with great difficulty to the present frontier region of approximately 2 to 3 millimeters wavelength. One would like to further extend these sources, which make possible numerous RF systems and techniques, another one to two orders of magnitude higher in frequency. While this may not be possible in the tubes themselves, it may be possible to use the tubes to drive a non-linear element to achieve harmonic power in the submillimeter region.

There has been increased activity in the area of non-linear elements recently, with indications of possible success. The non-linear element can assume a number of forms, for example: (1) a silicon crystal, (2) a ferrite, (3) a gas discharge, (4) a field emitter, (5) an electron beam, etc. In principle one seeks the highest frequency, highest power microwave source to drive the most non-1inear, high power level element.

The present program being followed by the Ultramicrowave Group involves: (1) silicon crystal multipliers for achieving low power level milimeter signals for bench testing and development of components, (2) field emitters as a possible medium power level cW harmonic source, and (3) a bunched megavolt beam for producing high pulsed power level si.gnals.

\subsection{Bunched Megavolt Beams as Non-1inear Elements for Use in Megavolt Electronics}

A schematic drawing of a megavolt electronics millimeter wave generation system, using an electron beam as a non-1inear element for: frequency multiplication, is shown in Fig. 1 . In this system, a high power microwave tube source at frequency $f_{0}$ drives a relativistic 


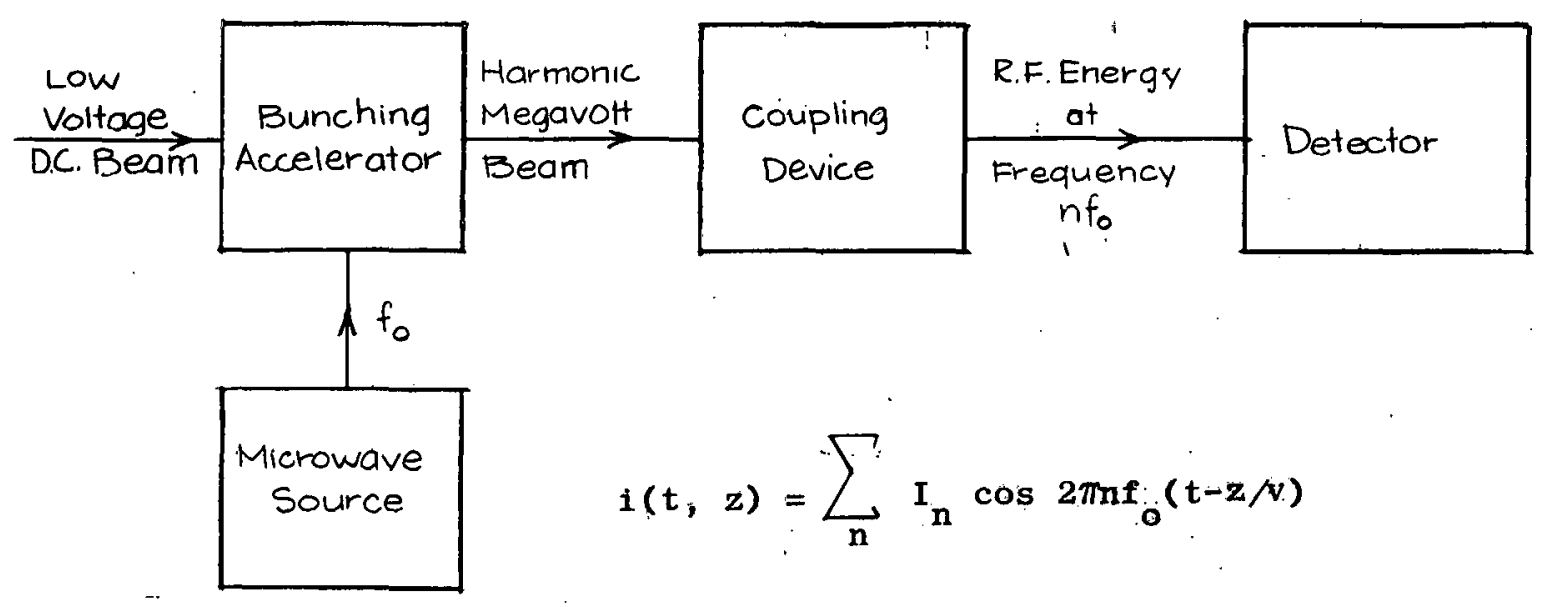

FIGURE 1 MEGAVOLT ELECTRONICS SYSTEM

electron bunching accelerator, called a REBATRON, which converts a low voltage $\mathrm{DC}$ beam into a bunched megavolt beam containing high current harmonic frequencies of the driving source. This harmonic beam, in turn, drives a coupling device which converts a part of the beam kinetic energy into RF energy at frequency $\mathrm{nf}_{\mathrm{o}}$.

A program on megavolt electronics, as seen from Fig. 1, involves three phases: (1) the production and evaluation of the bunched megavolt beam, (2) the study of beam coupling structures, and (3) the development of detectors and measuring components.

The problem of creating a high energy bunched electron beam has been initially solved in a very compact relativistic electron accelerdtor and buncher, called a REBATRON which is illustrated in Fig. 2. This device consists of a single $\mathrm{TM}_{010}$ mode microwave cavity driven by a high power magnetron. A simple prebunching system is used to inject electrons into the accelerator. This system consists of a Pierce gun, modulating cavity, and drift distance arranged to give the entrance beam a desirable velocityphase relationship to achieve good bunching in the accelerating cavity.

Theoretical calculations have given a computed harmonic content in the exit beam of appreciable value to as high as the $1000^{\text {th }}$ term in the Fourier series representation of the current. Furthermore, the velocity spectrum of the accelerated electrons is sufficiently peaked that the beam can be quite accurately represented as a traveling current wave of the form 


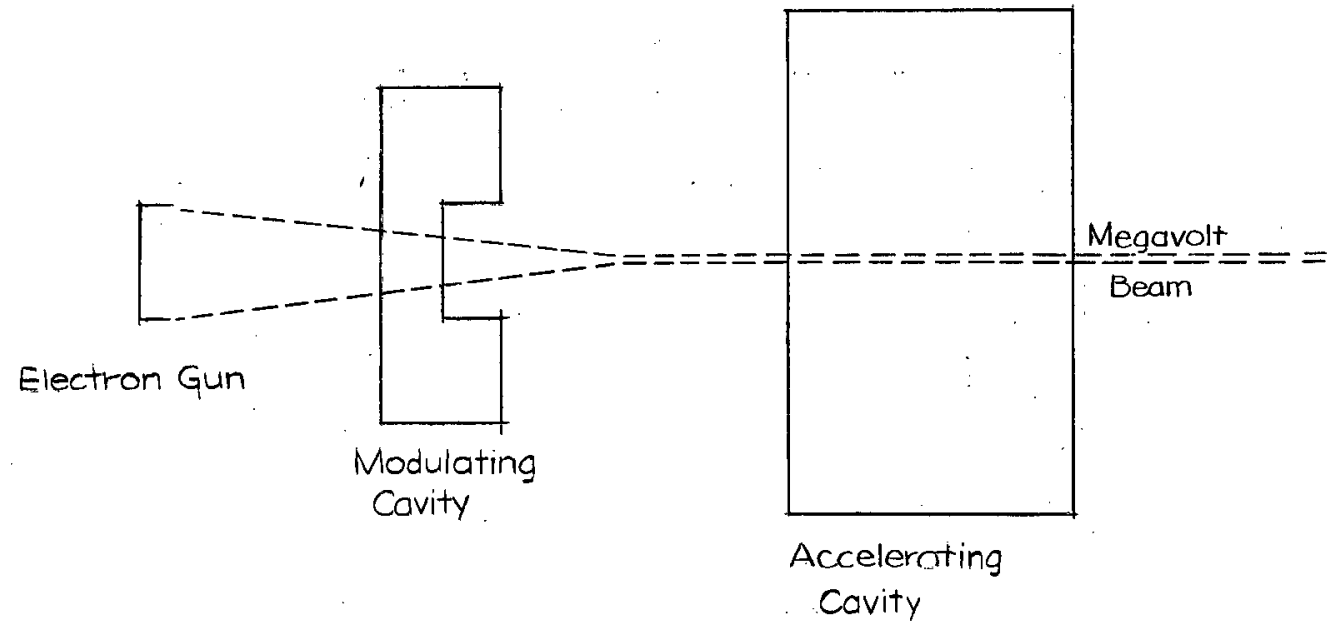

FIGURE 2 REBATRON STRUCTURE

$$
i(t, z)=\sum_{s} I_{s} \cos 2 \pi s f_{0}(t-z / v)
$$

where

$$
I_{S} \simeq 2 I_{0}
$$

and

$$
\because \simeq c
$$

The theoretical calculations are of necessity somewhat idealized so that, coupled with the tolerance problem, it is hoped that in practice it will be feasible to use harmonics up through the $100^{\text {th }}$. Power at the $35^{\text {th }}$ harmonic of the S-band rebatron has already been achieved, with work in progress to extend the useable harmonic power to one millimeter wavelength.

To produce power below one millimeter wavelength, an $\mathrm{X}$-band $(3 \mathrm{~cm})$ bunching accelerator is being developed. This device will use the rebatron structure followed by a, short linear accelerator: section to accelerate the bunched beam into the 1 to $3 \mathrm{mev}$ range. The linear accelerator section is necessary since sufficient voltage cannot be developed across a $\mathrm{TM}_{010}$ mode cavity at $\mathrm{X}$-band to achieve megavolt beams without voltage breakdown in the structure. 




FIGURE $3 \quad \mathrm{X}$-BAND BUNCHING ACCELERATOR

\subsection{Megavolt Coupling Structure Research}

The coupling structure work is along two lines: (1) the excitation of the higher order modes of a system to solve the physical size limitation problem, and (2) non-resonant Cerenkov structures.

It is well known that a structure oscillating in a higher order mode can be physically large compared to the resonant wavelength. For example, in the case of the TM omn mode cylindrical cavity shown in Fig. 4 by using large values of the indices, $m$ and $n$, it is seen that $D / \lambda_{0}$ and $L / \lambda_{0}$ can be made much greater than one.

$$
\left(\frac{\mathrm{D}}{\lambda_{\mathrm{o}}}\right)^{2}=\left(\frac{\mathrm{r}_{\mathrm{om}}}{\pi}\right)^{2}+\left(\frac{\mathrm{nD}}{2 \mathrm{~L}}\right)^{2}
$$

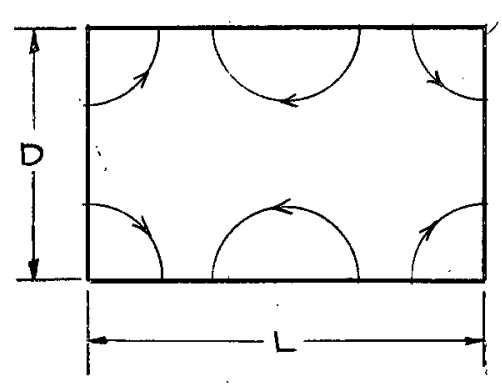

$$
\begin{aligned}
\frac{\mathrm{v}_{\mathrm{p}}}{\mathrm{c}} & =\sqrt{1+\left(\frac{\mathrm{r}_{\mathrm{om}} 2 \mathrm{~L}}{\pi \mathrm{hD}}\right)^{2}} \\
\mathrm{k}_{+} & =\frac{1}{2} \frac{\sin \left[\frac{\pi \mathrm{L}}{\lambda_{\mathrm{o}}}\left(\frac{\mathrm{c}}{\mathrm{v}}-\frac{\mathrm{c}}{\mathrm{v}_{\mathrm{p}}}\right)\right]}{\left[\frac{\pi \mathrm{L}}{\lambda_{\mathrm{o}}}\left(\frac{\mathrm{c}}{\mathrm{v}}-\frac{\mathrm{c}}{\mathrm{v}_{\mathrm{p}}}\right)\right]}
\end{aligned}
$$

FIGURE 4 EXCITATION OF TM OOMn MODES OF CYLINDRICAL METAL CAVITY

Two problems are involved in exciting higher order mode structures: (1) the mode interference problem, and (2) the coupling problem, as seen from Eqs. 3 and .4. The power given up by the beam can be expressed as

$$
\rho \simeq \frac{1}{2}\left(I_{s} k_{t}\right)^{2} R
$$


where $\mathrm{k}_{+}$is the coupling coefficient given by Eq. 4, and $\mathrm{R}$ is the circuit interaction resistance. Unless $\mathrm{v} \simeq \mathrm{c}$, very little power could

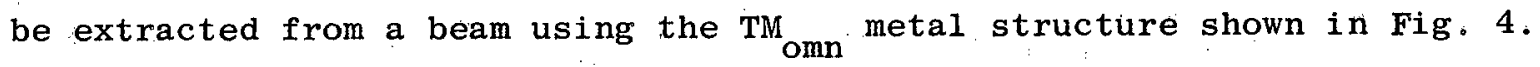
However, using a beam velocity $v \geqslant 0.93 \mathrm{c}$, it has been shown that modes up to the $\mathrm{TM}_{02(10)}$ and $\mathrm{TM}_{03(10)}$ are practical without using mode suppression techniques. Thus a simple structure, large enough to be fabricated conveniently, can be made to produce radiation below one millimeter.

The current work is directed towards finding a structure whose phase velocity is in the range $0.93 \mathrm{c} \leq \mathrm{v}_{\mathrm{p}} \leq 1$ and whose higher order modes can be well separated so as not to cause mode interference. A structure which shows considerable promise in this direction is the dielectric cavity shown in Fig. 5 .

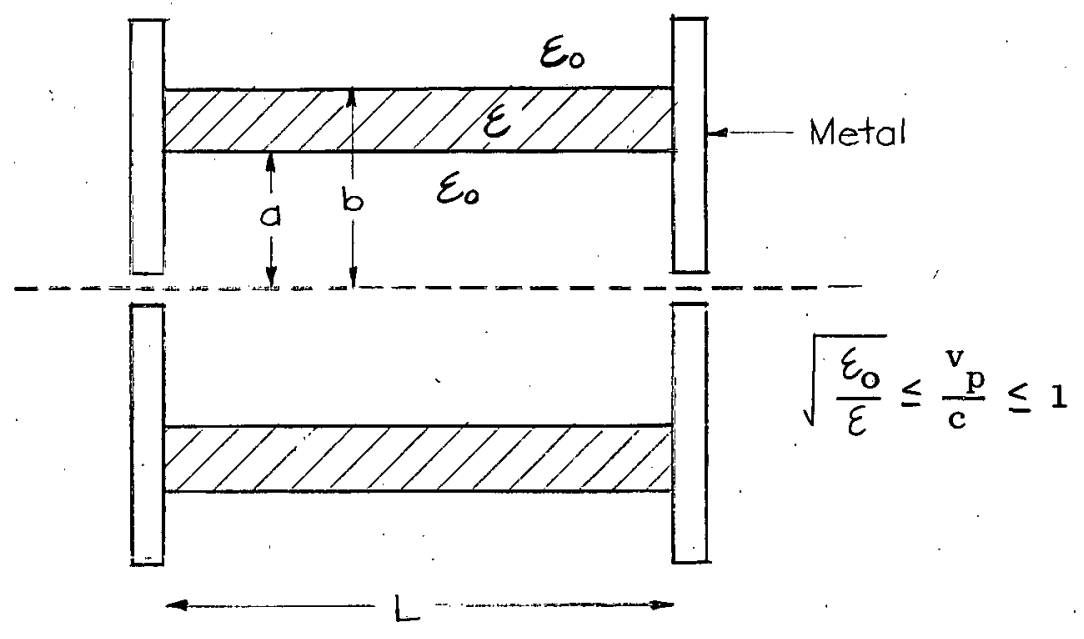

FIGURE 5 DIELECTRIC HARMODOTRON

This structure behaves as a high $Q$ cavity only for those modes whose phase velocity is less than the velocity of light $c$, so that some mode suppression is inherent in the device. Also, since there are two additional parameters $b$ and $\varepsilon$ associated with this device as compared to the metal structure, additional mode separation can be achieved。

Work is in progress in evaluating the mode properties (a very tedious numerical task) of these structures and the power output that 
can be achieved. Initial experiments have checked very well with theory, using a $\mathrm{TM}_{01}$ (13) mode at eight millimeters wavelength.

The Cerenkov structure being investigated is a split dielectric cone, as shown in Fig: 6. The cone has been split into two equal sections, the

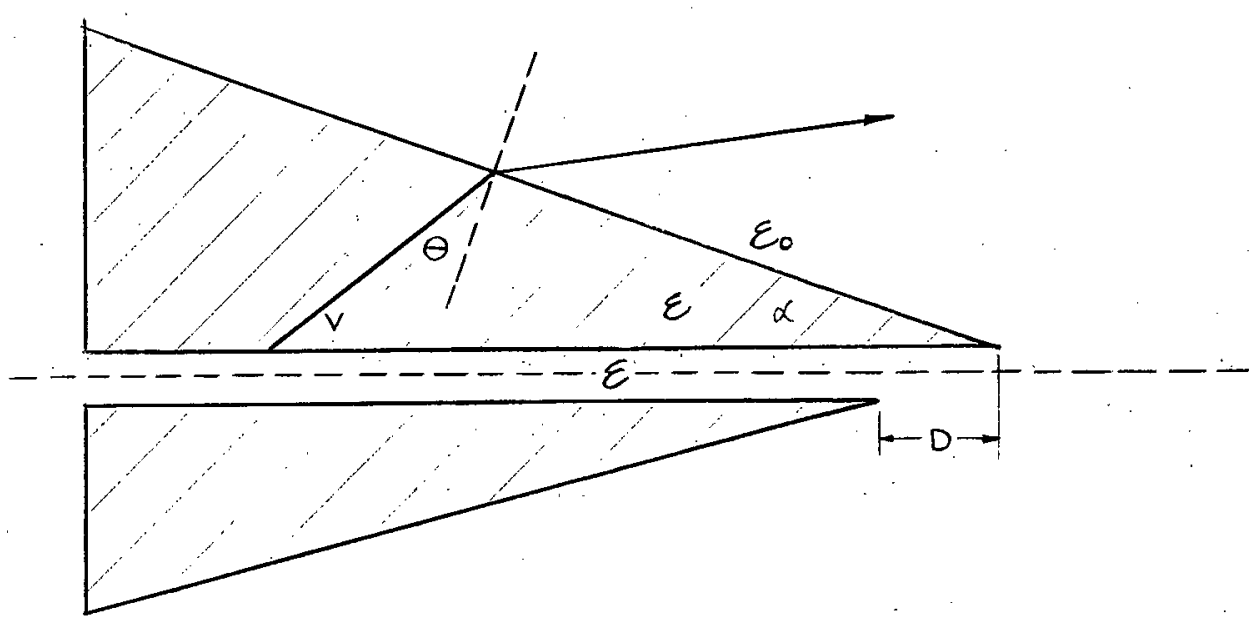

\section{FIGURE 6 CERENKOV RADIATOR}

one section then displaced a distance $D$ relative to the first, to destroy part of the circular symmetry and make the radiator end fire.

The advantage of a megavolt beam is again evident when one examines the $\mathrm{E}_{\mathrm{z}}$ field component in the axial hole traversed by the beam.

$$
E_{z}=E_{o}\left\{a_{n} I_{o}(K r)+\frac{\rho_{n}}{K^{2} \varepsilon_{o}}\right\} \varepsilon^{i n \omega_{o}(t-z / v)}
$$

where

$$
K=\frac{2 \pi}{\beta \lambda} \sqrt{1-\beta^{2}}
$$

and

$$
\mathrm{v}=\beta \mathrm{c} .
$$

As $\beta \rightarrow 1, K \rightarrow 0$ and the field becomes more uniform in the $r$ direction, so that the beam does not need to pass close to the dielectric. 


\subsection{Detectors and Components:}

The present aim of this work is to develop a set of two and one millimeter components around $0.075 \times 0.034$ inch and $0.049 \times 0.0221$ nch guide, for use in microwave diagnostics of gaseous plasmas.

The signal source for testing components has been the silicon crystal cross gulde multiplier, using QK288 and EMI (R9521) eight millimeter klystrons as drivers. Numerous new mechanical and electrical designs are being tried to improve these multipliers to increase their output power. An Amperex $\mathrm{DX}-151$ four millimeter klystron and an Elliott Brothers VX 9206 eight millimeter klystron are being secured for drivers of new. multiplying devices.

The machining and mechanical problems of fabricating one millimeter wavelength components have been largely solved. What is needed is better signal sources so that the electrical designs can be improved and better evaluated.

\subsection{Present Status of the Work}

\subsubsection{Rebatron Research}

\subsubsection{S-Band Rebatron}

The work on our present $\mathrm{S}$-band rebatron is concerned with:

(1) improving the electron bunching, current and beam focusing, and

(2) the design of a portable prototype system. Most of the parts for this new machine have been fabricated and tested during this quarter and the construction initiated. A photograph showing the present stage of construction is given in Section 3.1.2.

\subsubsection{X-Band Rebatron}

An $\mathrm{S}$-band rebatron cannot be scaled directly to $\mathrm{X}$-band since sufficient voltage to produce a megavolt beam cannot be developed in a $\mathrm{TM}_{010}$ mode X-band cavity because of voltage breakdown. However, a lower voltage $X$-band rebatron $;$ followed by a short section of a linear accelerator, could solve the problem.

An Electronics Associates analog computer was received during this quarter and is being programmed to explore the design problems. Final detailed calculations can be made on the ILLIAC digital computer. 


\subsubsection{Magnetron Stabilization}

Work has been initiated on two new schemes for getting more of the magnetron power into the high $Q$ accelerating cavity: (1) a gas discharge switch, and (2) some new high power ferrite isolators.

\subsubsection{Beam Coupling Schemes}

The tedious numerical work of evaluating the TM and TE modes of our teflon dielectric cavities is largely completed.

The submilimeter experiment at $\lambda_{0}=0.982$ millimeters $\left(110^{\text {th }}\right.$ beam harmonic of our S-band rebatron) using a dielectric harmodotron was not successful. It is believed that the same factors--namely, (1) having to position the coupling structure on the order of $15 \mathrm{~cm}$ from the rebatron, (2) small electron beam entrance hole in the coupling structure-that were previously encountered reduced our harmonic current below a usable value. Figure 9 shows a new cavity which should help to solve this problem.

\subsubsection{Detecting and Measuring Techniques}

New ideas and further modifications are being tried in our silicon crystal harmonic multipliers for use as sources for testing components. Our latest ideas involve the use of a straight guide tapered down in the narrow dimension to limit the number of harmonic standing waves that can exist on the tungsten whisker antenna. This construction reduces the fabrication problems involved in the crossed waveguide multiplier and decreases the frequency sensitivity.

The new EMI VX 5023T (R9521) klystrons now being used permit driving the crystals harder, and hence improve the harmonic power.

\subsection{Personne1}

The present staff assigned to Contract AT(11-1)-392 includes:

\section{Supervision}

Paul D. Coleman, Associate Professor, Director

Murray D. Sirkis, Research Assistant Professor Associate Director

Staff

Richard Pantell, Visiting Assistant Professor Andrew Swago, Instructor

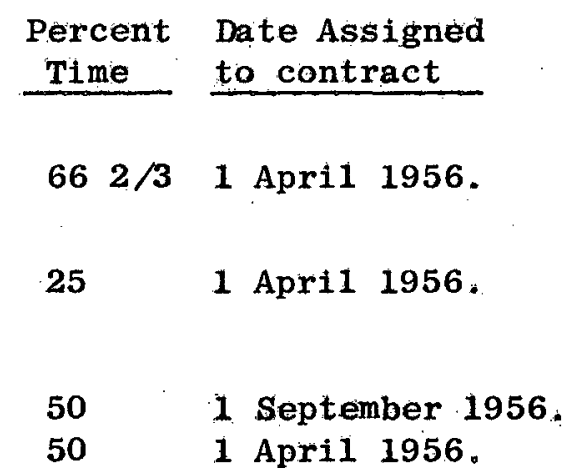


Research Associates and Assistants

Harold Spuhler, Research Associate Richard Kenyon, Research Assistant Richard Becker, Research Assistant

$\begin{array}{rl}75 & 1 \text { September } 1956 \\ 75 & 1 \text { April } 1956 \\ 100 & \text { I December } 1956 .\end{array}$

Electronic Technicians

Kenneth Bartlett, Sr. Elec. Tech. Allen B.Wilson, Sr. Elec。Tech, Jack Baird, Student (Hourly) Garry Paddick, Student (Houriy) Joseph Stafford, Student (Hourly) Robert Strain, Student (Hourly)

$$
80
$$

33

( $\sim 15$ hours wk)

( $\sim 15$ hours wk)

( 15 hours wk)

( 15 hours wk)
1 April 1956.

1 Apri1 1956.

1 June 1956.

1 June 1957.

1 February 1957.

1 June 1956.

Shop Technicians

John F. Lowe, Instrument Maker

$100 \quad 1$ April 1956.

Lewis Claybaugh, Senior Laboratory Mechanic $\quad 75 \quad 1$ March 1957.

Clerks

Donald Pritchard

$25 \quad 1$ April 1956.

Richard Ripper

1 April 1956.

R. Panteli left the project on 30 June 1957 to return to Stanford University。 M.D. Sirkis left the project on 31 August 1957 to accept a position at Rutgers University.

All personnel took all or part of their annual vacation during this period:

\subsection{Papers, Reports, Publications, Visits}

2.7.1 Quarterly Reports

"Title Report Period

Quarterly Report No. 1

1 March to 1 June 1956

Quarter1y Report No. 2

1 June to 1 September 1956

Quarterly Report No. 3

1 September to 1 December 1956

Quarter1y Report No: 4

1 December to 1 March 1957

Quarterly Report No. 5

1 March to 1 June 1957

\subsubsection{Technical Reports}

The Harmodotron-A Beam Harmonic Higher Order Mode Device for Producing Millimeter and Submillimeter Waves," M.D. Sirkis, Technical Report No. 1, 10 September 1956. 


\subsubsection{Conference Papers}

${ }^{x t}$ Megavolt Electronics and the Submillimeter Wave Problem," presented by. P.D. Coleman at the Fourteenth Annual Conference on Electron Tube Research, June 1956, Boulder, Colorado。

\subsubsection{Papers Accepted for Publication}

The following papers will appear in the September issue of the Journal of Applied Physics:

1. The Theory of the Rebatron--a Relativistic Electron Bunching Accelerator for Use in Megavolt Electronics, P.D. Coleman.

2. The Design and Evaluation of a $3 \mathrm{kmc}$ Rebatron, ${ }^{80}$ I. Kaufman and $P_{6} D_{0}$ Coleman (this paper was jointly supported by Contracts $\operatorname{AT}(11-1)-392$ and $\operatorname{AF1} 1(603)-62$.

3. ${ }^{30}$ The Harmodotron--A Megavolt Electronics Millimeter and Submillimeter Wave Generator," M.D. Sirkis and P.D. Coleman.

The following paper has been submitted for publication:

${ }^{19}$ Dielectric Slow-Wave Structures for the Generation of Power at Mi11imeter and Submiliimeter Wavelengths, R. R.H. Pantel1, P.D。Coleman, R。C o Becker。

\section{$2.7{ }_{b} 5$ Visits and Conferences}

P. Coleman and M. Sirkis attended the Annual Conference on Electron Tubes held at the University of California, Berkeley, and visited Stanford, Varian Associates, and the General Electric.Co., to discuss millimeter wave generation and new tube developments.

$\mathbf{P}_{0 .}$ Coleman visited Charles Wharton at Livermore to review microwave plasma diagnostics.

$P_{. b}$ Coleman also visited Linfield Research Institute at McMinnville, Oregon, where he gave a seminar talk and investigated the use of a field emitter as a frequency multiplying element for the low millimeter range

During quarterly report period No.4, visits were made to Duke University, Johns Hopkins University, Naval Research Laboratory, Bell Telephone Laboratories (Murray Hill and Holmdel), New York University, Columbia University, Sylvania Electric Products Co., Inc., (Bayside), R.C.A.Laboratories (Princeton), Evans Signal Laboratory (Belmar), and Brooklyn Polytechnic Institute, to discuss millimeter wave generation, so that a fairly complete survey has now been made. 


\section{DETA ILED FACTUAL DATA}

\section{$3.1 \quad$ Rebatron}

\subsubsection{Purpose}

The objective of this phase of the program is the design and development of a practical, compact, portable rebatron. There are four subphases to this work.

1. Microwave circuit problem

2. Electron injection problem

3. Electron trajectory calculations

4. Electronic instrumentation problem.

3.1.2 Electron Injection Problem - R. Kenyon

\section{1 .2 .1 Purpose}

The aim of this work is to investigate the electron dynamics problem in the rebatron from the point of view of increasing the accelerated current to its largest practical value.

\subsubsection{Present. Status}

At the present time, the test accelerating cavity has been made and the coupling hole size is now being determined. Drawings for the final accelerating cavity are now in the machine shop. An E-plane bend has been made out of brass in order to see how well it is matched. The measurement was performed by terminating the E-plane bend with a matched load and measuring the VSWR of the combination: The VSWR of the matched load was determined to be 1.08 , and that of the combination to be 1.15 , indicating that the E-plane bend is well enough matched for its purpose. Two demountable vacuum window seals and the vacuum manifold have been fabricated and assembled. Three spacers for the injection tube have been designed and built. A panel mount for the vacuum valves and thermocouple gauge has been designed and built. The vacuum table proper has been designed and built. Figure 8 shows the portable table in its present stage of construction with the single magnetron accelerating cavity on top of the table. Figure 7 is shown to permit comparison in size between the present rebatron and the new portable rebatron. 


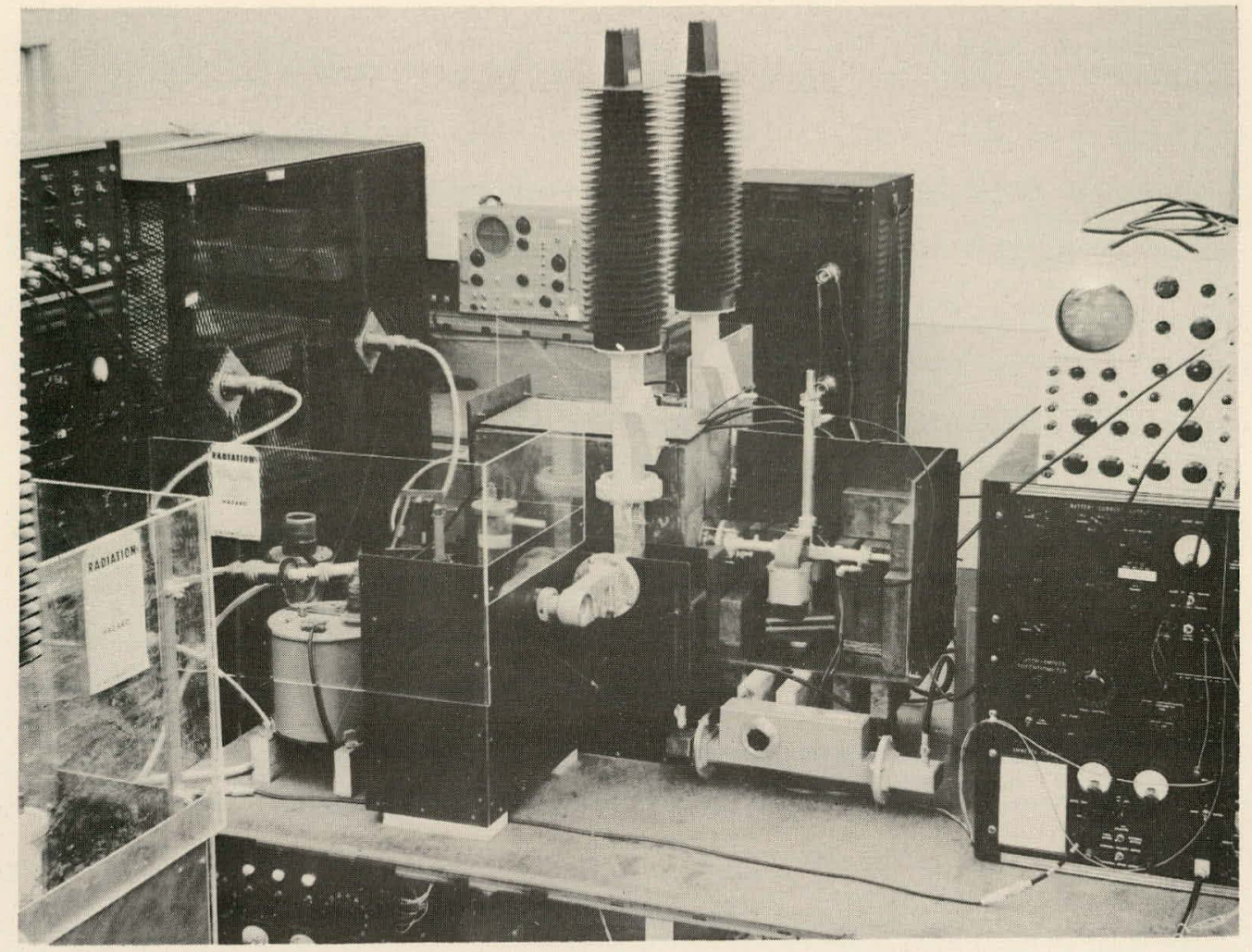

FIGURE 7 PRESENT S-BAND REBATRON

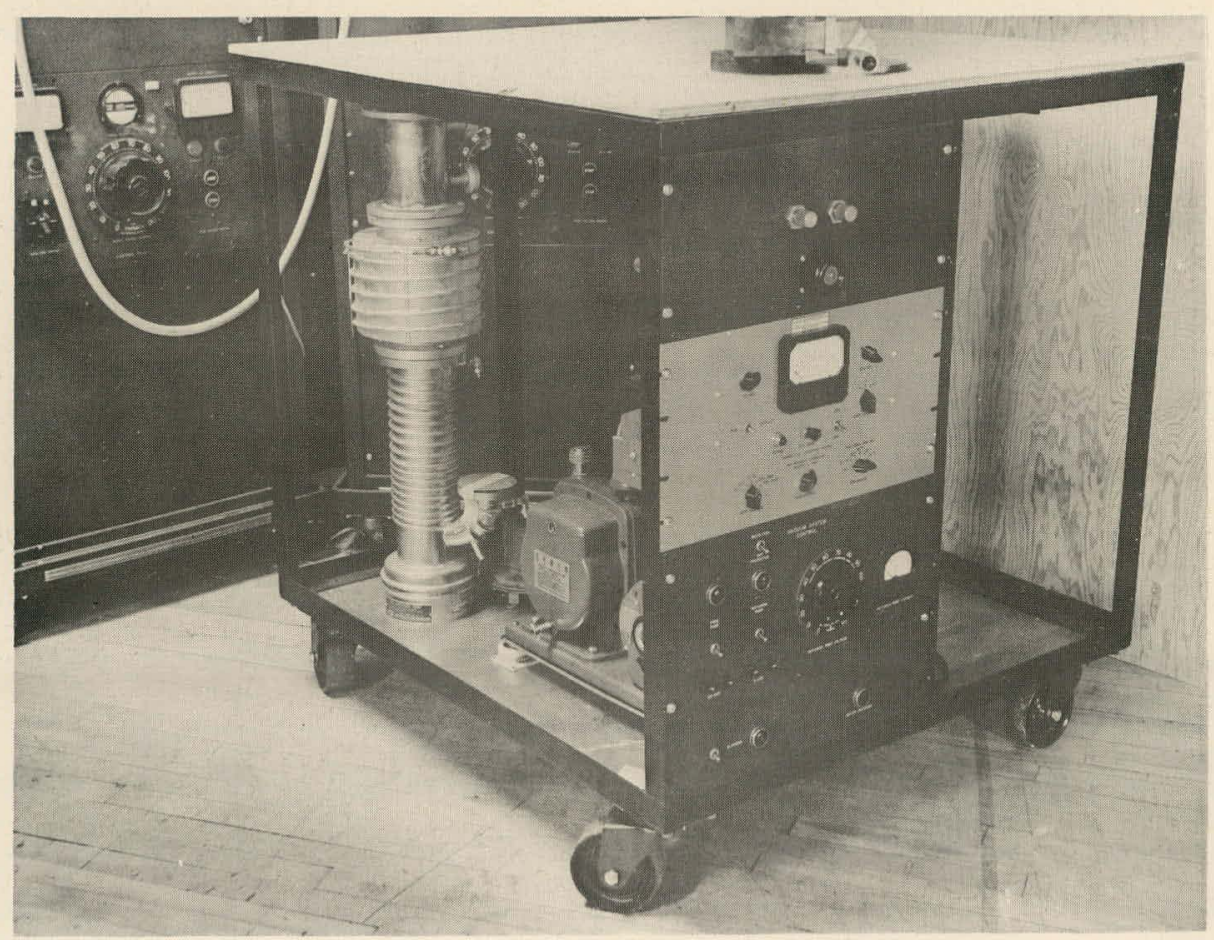

FIGURE 8 NEW PORTABLE S-BAND REBATRON UNDER CONSTRUCTION 
A supplier for OFHC waveguide has been located and six feet of wavegulde has been purchased. A supplier for $40 \mathrm{kv}$ vacuum bushings has been located and two bushings have been purchased for testing.

Some work on the design of a new injection tube has been completed. The design equations were rearranged into the form that was most convenient for the specifications (this had not been done before) and a number of calculations were made on different design specifications for a $4^{\circ}$ halfconvergent angle gun. Iimitations on voltage may require that a larger half $\times$ convergent angle than $4^{\circ}$ be used to supply $300 \mathrm{ma}$.

\subsubsection{Rebatron Design above $3 \mathrm{kmc} / \mathrm{s}-\mathrm{H}$. Spuhler}

\subsubsection{Purpose}

The purpose of this phase of the project is two-fold:

1. To investigate the problems involved in operation of a rebatron at frequencies above $3 \mathrm{kmc} / \mathrm{s}$ and to determine the highest frequency useable, considering components presently available.

2. To construct and test a rebatron operating at the highest frequency above $3 \mathrm{kmc} / \mathrm{s}$ for which design factors are practical.

\subsubsection{Present Status}

Magnetron power available at the frequency of interest $(9.3 \mathrm{kmc} / \mathrm{s})$ will permit single-tube operation up to 500 kilowatts peak pulsed power at the pulse lengths required. Inasmuch as one aspect of the problem concerns the compactness of the associated equipment, the limitation of available power to this level has required a reexamination of the approach to the problem.

The $10 \mathrm{~cm}$ rebatrons now in operation were designed to use a single cavity, operating in the $\mathrm{TM}_{010}$ mode, as the accelerating section. With 400 kilowatts pulsed power delivered to such a cavity, peak gap voltages of the order of 1.5 megavolts are obtained across gaps of about $4 \mathrm{~cm}$ without exceeding breakdown intensities, taken to be about 0.55 megavolts per centimeter. Scaling the design for $3 \mathrm{~cm}$ operation in the same mode has shown that this gap voltage cannot be obtained without exceeding breakdown intensities if gap lengths are chosen for the single transit case and multiple transits are excluded. For example, if the peak pulsed power delived to the cavity is 250 kilowatts, only half that available, 
the gap length must be greater than $3 \mathrm{~cm}$ to keep below breakdown intensity. Thus transit phase angles would be considerably greater than $\pi$ radians, unless high injection velocities were used, which, in turn, would make the bunching problem more difficult. If the gap length is shortened to obtain shorter transit phase angles, the power delivered to the cavity must be reduced to avoid breakdown; hence the field intensities, which should be high for good bunching, will be reduced.

Results of the calculations for cavities operating in higher-order modes indicate that, while such operation would avoid the breakdown problem, to successfully match the injection system to the accelerating system an additional structure would be necessary to bring the bunch velocity up to that level which would permit capture by the forward traveling wave of the accelerator.

Several possibilities occur here. Two seem to be practical from the viewpoint of adapting the present design. One would utilize the present rebatron configuration as a buncher for an accelerator consisting of one section with tapered phase velocity and a Iollowing one with constant phase velocity. Thus the tapered section would serve to match the buncher to the linear section. Indications are that this method would produce closer bunching than that obtained by using the tapered section as a buncher.

The other method would utilize a linear slow-wave structure, with phase velocity about $0.97 \mathrm{c}$, preceded by a modulation scheme intended to match the ideal injection conditions necessary for the spatial and energy distributions desired at the accelerator termination. This method is the same as used in previous rebatron designs except that the final stage is a linear accelerator section rather than a single cavity.

Both of these methods are being studied. Programs have been written for the analog computer made available this summer. Preliminary calculations will be made on it. An ILLIAC program is being written for the tapered section to permit detailed examination of its orbital characteristics. ILLIAC programs for the single cavity case and for the linear accelerator section are already available so that overall performance characteristics can be investigated when the program for the tapered section is completed. 


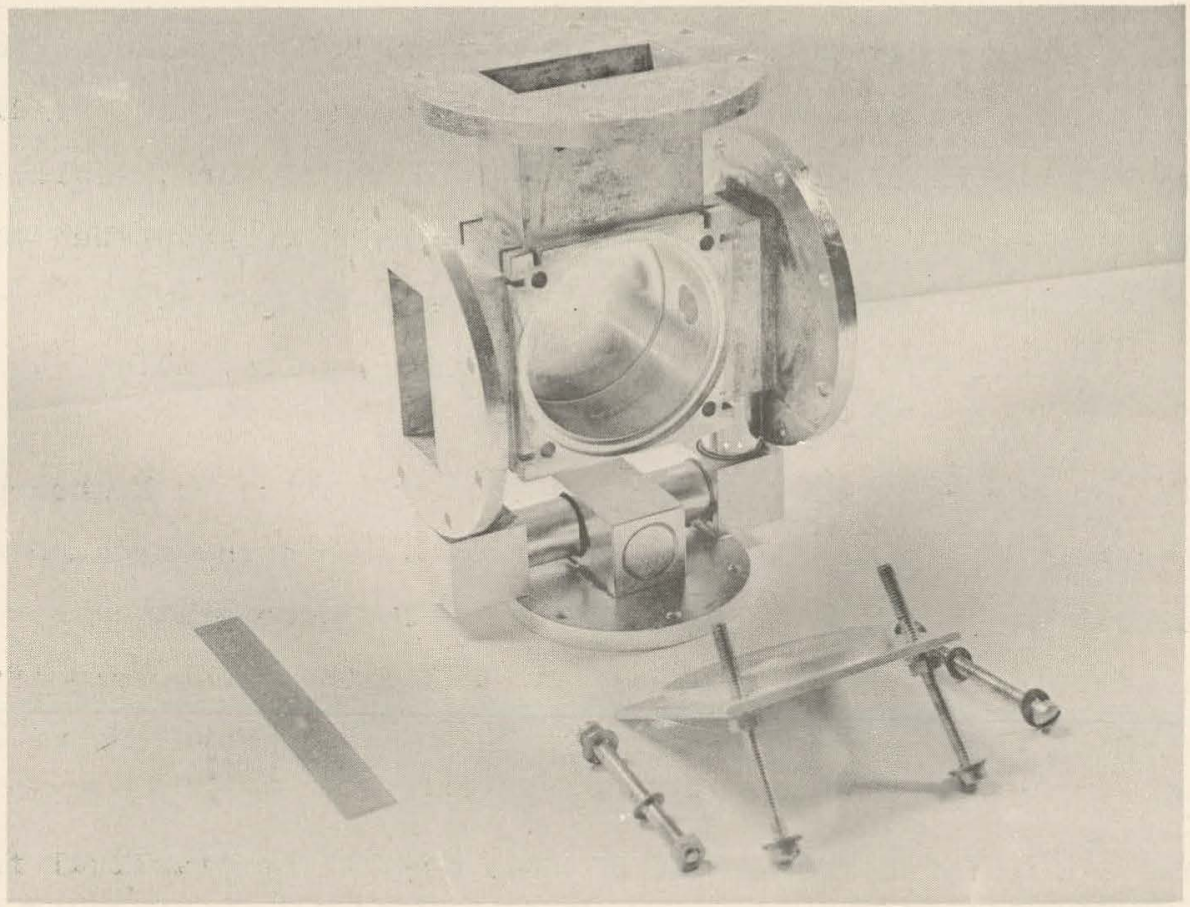

FIGURE 9 NEW S-BAND REBATRON CAVITY WITH REMOVABLE END WALL FOR ATTACHING COUPLING STRUCTURE DIRECTLY TO EXIT BEAM HOLE



FIGURE 10 CRYSTAL MULTIPLIERS WITH TWO AND ONE MILLIMETER COMPONENTS 


\subsubsection{Magnetron Stabilization}

An investigation of means for maintaining magnetron stability when firing into high $Q$ cavities is under way.. Present means of stabilization involves use of a tee with resistive loading. The method used by Krusemeyer ${ }^{1}$ will be tried. In this case the cavity is coüpled to the side arm of an $\mathrm{H}$-plane tee matched for unity transformation ratio. The other arm is terminated with a slotted section enclosing an evacuated glass tube centered in the guide with axis normal to the broad face of the guide. The slotted section is terminated with a matched load.

Sinee the load will be in the system until ionization of the residual. gas takes place in the tube, it is expected that it will provide sufficient stabilization to permit buildup of oscillations in the cavity before. ionization, at which time the load will be switched out of the system by the action of the shorted section, so that most of the available power will be delivered to the cavity. Means have been provided for varying both the internal pressure and the position of the glass tube so that optimum conditions for maximum power to the cavity may be determined experimentally.

3.1.4 New Accelerating Cavity Design - M.D. Sirkis

\section{$3,1,4$ Introduction}

A new s-band accelerating cavity, having a removable end wall, has finally been hydrogen brazed, using a furnace in the Ceramics Department. The problems with the steel container used to confine the hydrogen atmosphere were solved sufficiently well to permit making the soldering operation. A photograph of the cavity is shown in Fig. 9 .

\section{$3.1,4,2$ Coupling Hole Measurements}

Three quantities must be determined for the cavity--its $Q$, resonant frequency $f_{\odot}$, and coupling hole diameter $D$. The method of measuring these parameters is illustrated in Fig. 11 .

FIGURE 11 COUPLING HOLE MEASUREMENTS






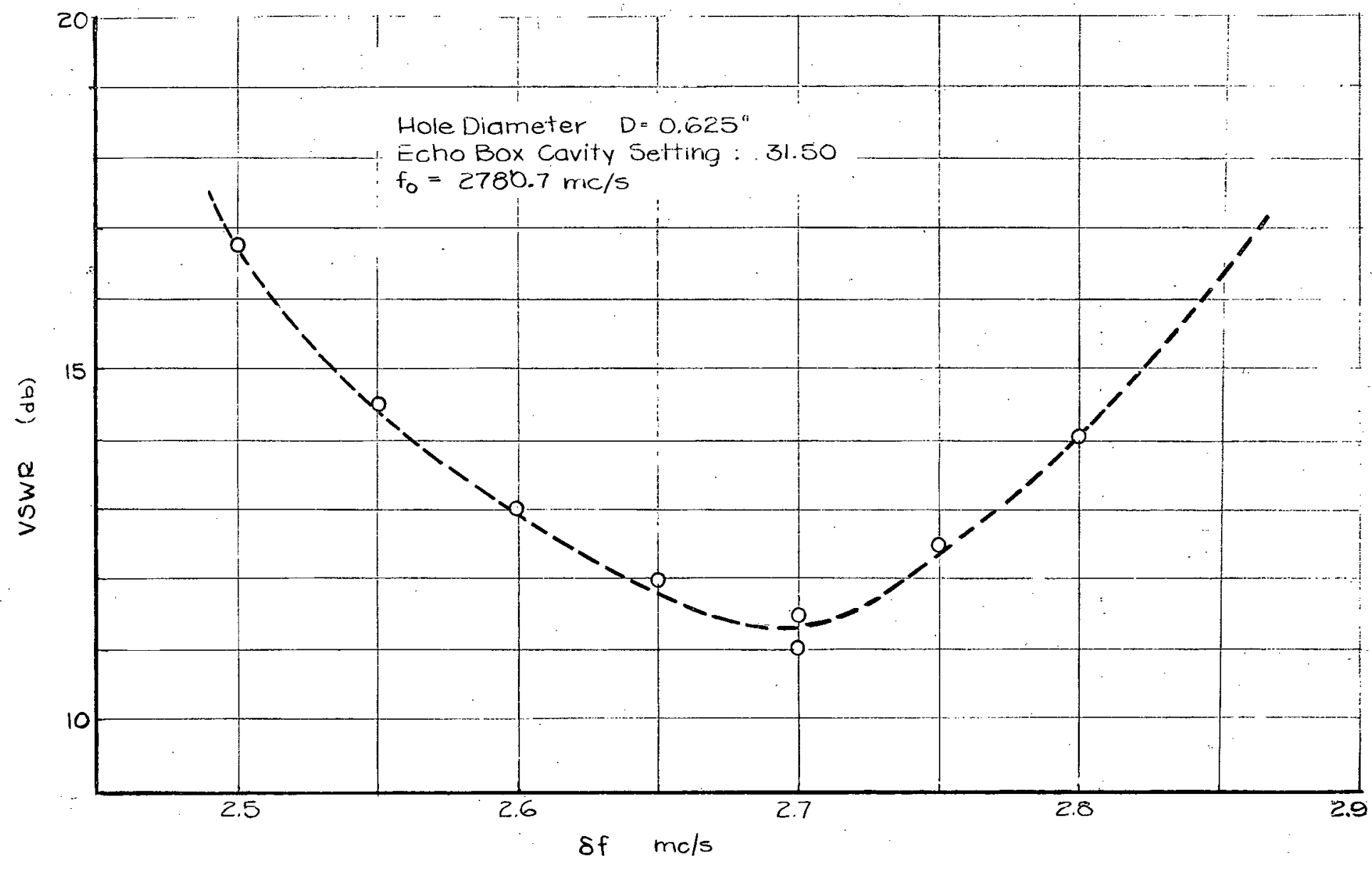

FIGURE 12 COUPLING HOLE MEASUREMENT NO 1 


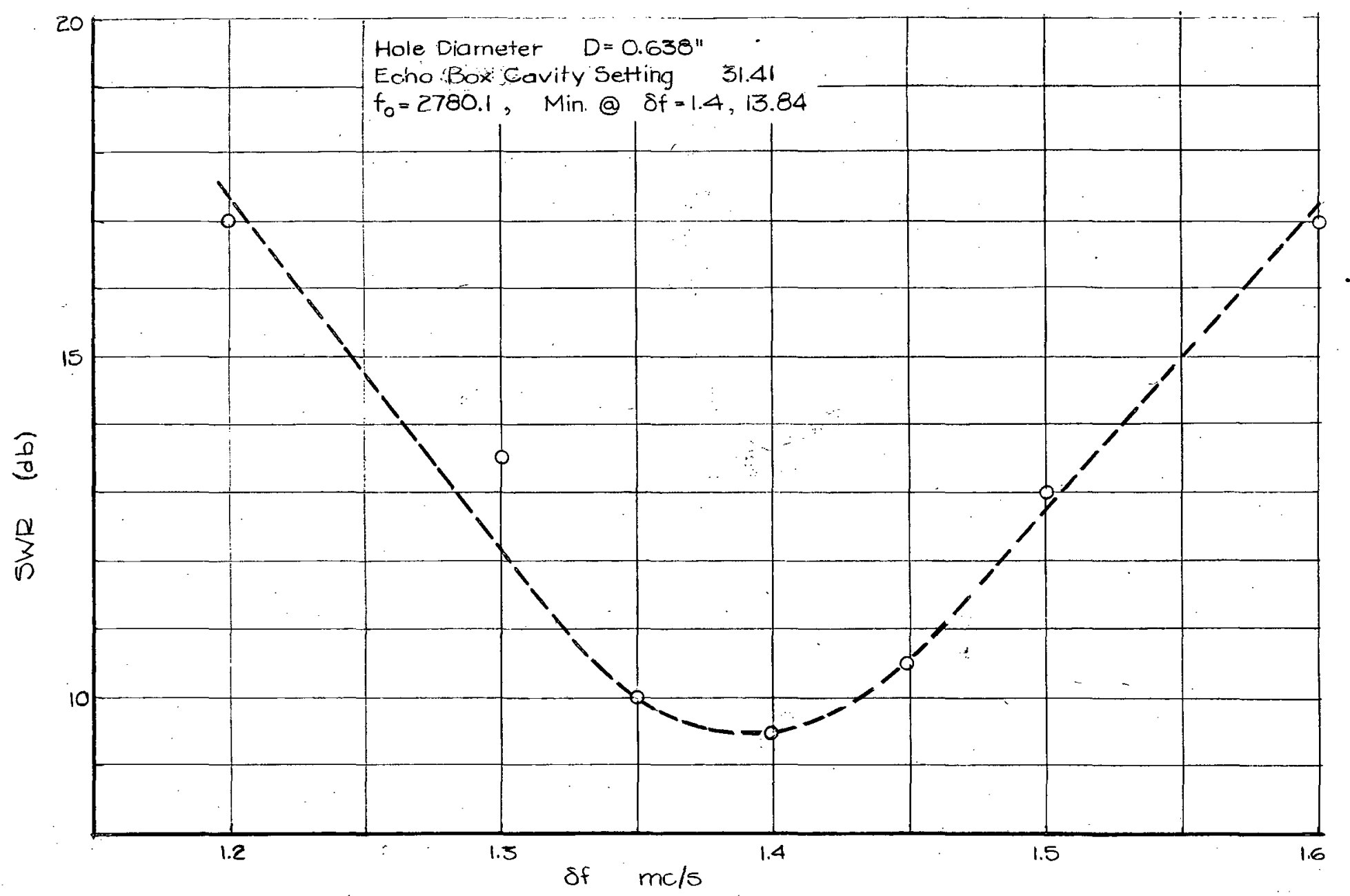

FIGURE 13 COUPLING HOLE MEASUREMENT NO. 2 




FIGURE 14 COUPLING HOLE MEASUREMENT NO. 3 


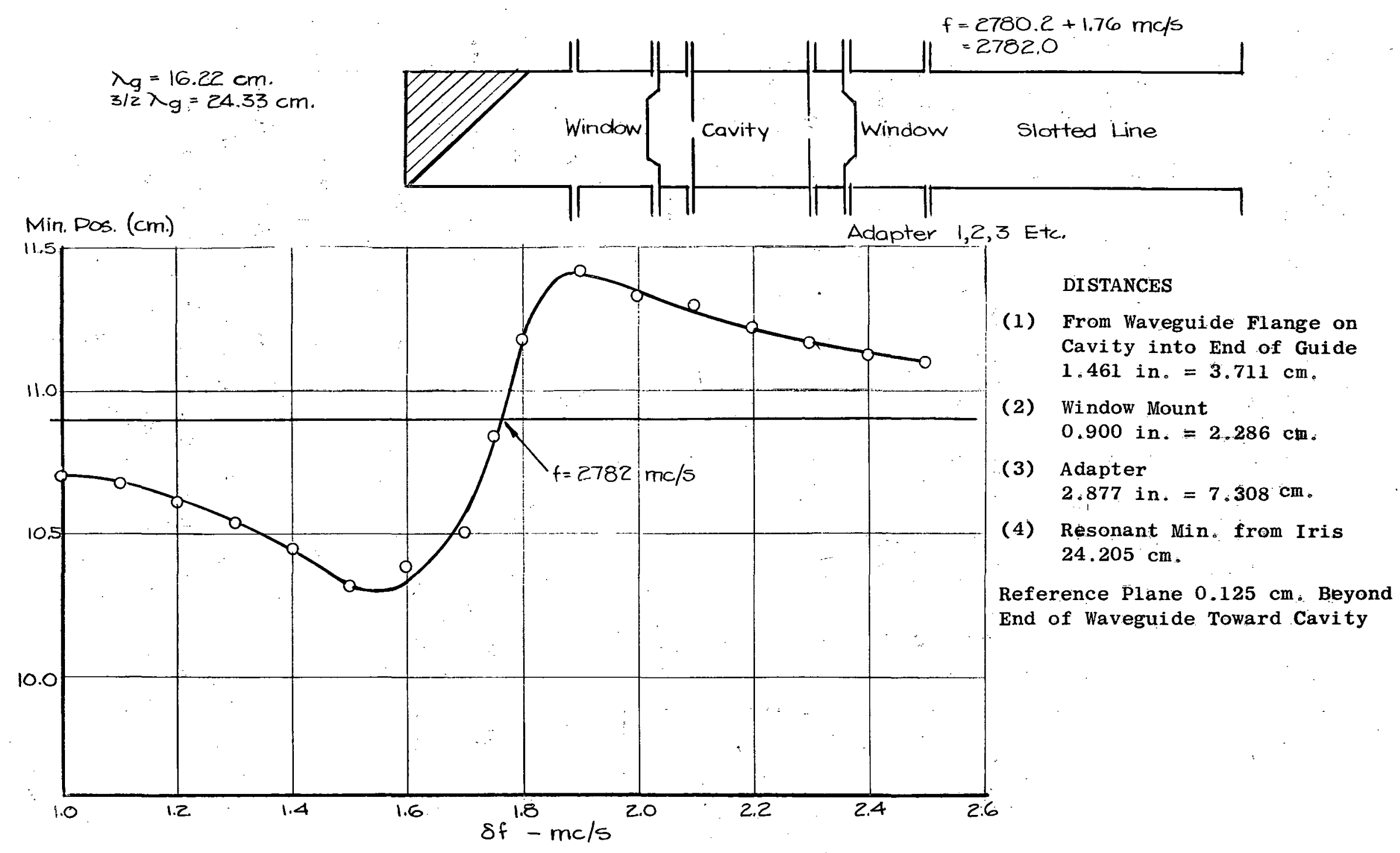

FIGURE 15 REFERENCE -PLANE MEASUREMENTS 
With the cavity terminated by a matched 1 oad $R_{0}$ on one side, the correct hole diameter D will give a 3 to 1 VSWR as measured on the second side. Figures 12, 13, and 14 show three sets of measurements made on the cavity for three different hole diameters.D.

The final hole diameter is seen to be $\mathrm{B}=0.643$ inch from Fig. 14 , with the resonant frequency $f_{0}=2782.6 \mathrm{mc} / \mathrm{s}$ and the unloaded $Q_{0}=12,000$ The important point to be noted is that the $Q$ of the cavity has not been seriously affected by having the top plate removable, which results in having a pressed fit at a high current point. How this joint will behave under high power is yet to be determined.

\subsubsection{Reference Plane Measurements}

The reference plane measurements are given in Fig. 15, along with a measured phase curve. It, is seen that the cavity is overcoupled, as it should be.

A summary of the pertinent dimensions associated with the cavity is given in Fig: 16. The flange of the cavity is connected to a section of

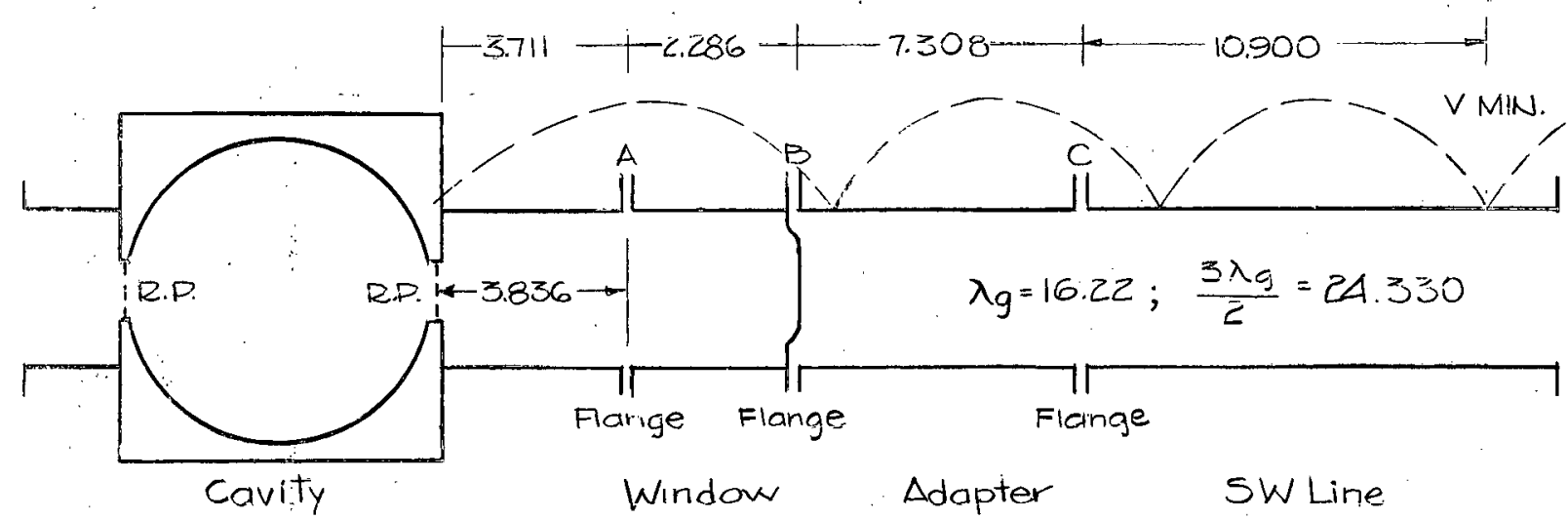

FIGURE 16 REFERENCE PIANES (Distances are in Centimeters)

guide containing a high power waveguide kovar window at point $\mathrm{A}$, using an "O $0^{\circ}$ ring. This arrangement permits easy cleaning of the cavity in a hydrogen furnace, if so desired. An adapter to protect the window bolts In the window section at $B$; hence the system is under vacuum to the left of $B$ and at atmospheric pressure to the right of $B$. 


\subsubsection{Tee for Magnetron Stabilization}

The series tee used for magnetron stabilization is shown in Fig. 17.






\subsection{Beam Coupling Schemes}

\subsubsection{Purpose}

This part of the research work has as its goal the origination of generation schemes using the million volt, bunched electron beam from the rebatron to produce high pulsed power in the 0.1 to $1 \mathrm{~mm}$ wavelength region of the electromagnetic spectrum. The general methods of approach to the problem are along two lines:

1) Extending existing tube techniques by means of megavolt electronics

2) Using the Doppler and Cerenkov effects in direct radiation devices.

3.2 .2 The Slow-Wave Dielectric Harmodotron - R. Becker

\section{$3.2,2,1$ Introduction}

In attempting to utilize the megavolt electronics approach to the problem of submillimeter wave generation, the slow-wave dielectric harmodotron (Fig. 18) has been conceived and shown to be a desirable beam coupling structure. The ability to regulate with relative simplicity the mode interference problem and the ability to realize considerably greater power outputs are two prime reasons for employing this type of coupling. device in preference to the harmodotron cavities initially investigated at this laboratory. A detailed investigation of the slow-wave dielectric harmodotron, involving both theoretical and experimental work, has been continuing, therefore, during the past interval. Specifically, TM mode charts have been computed, the expression for the power output of this device to a matched load has been derived, power outputs have been calculated for several cases, and preparations have been made for performing experiments at wavelengths of approximately one and two millimeters.

\subsubsection{Article for Publication}

During the past interval a paper entitled ${ }^{80}$ Dielectric slowWave Structures for the Generation of Power at Millimeter and Submillimeter Wavelengths, ${ }^{80}$ was prepared by Richard H. Pantell, Paul D. Coleman, and Richard C. Becker. The article compares the relative merits of the harmodotron, the dielectrically-loaded harmodotron, the dielectric harmodotron, and Cerenkov radiators for use as coupling devices within the scope 


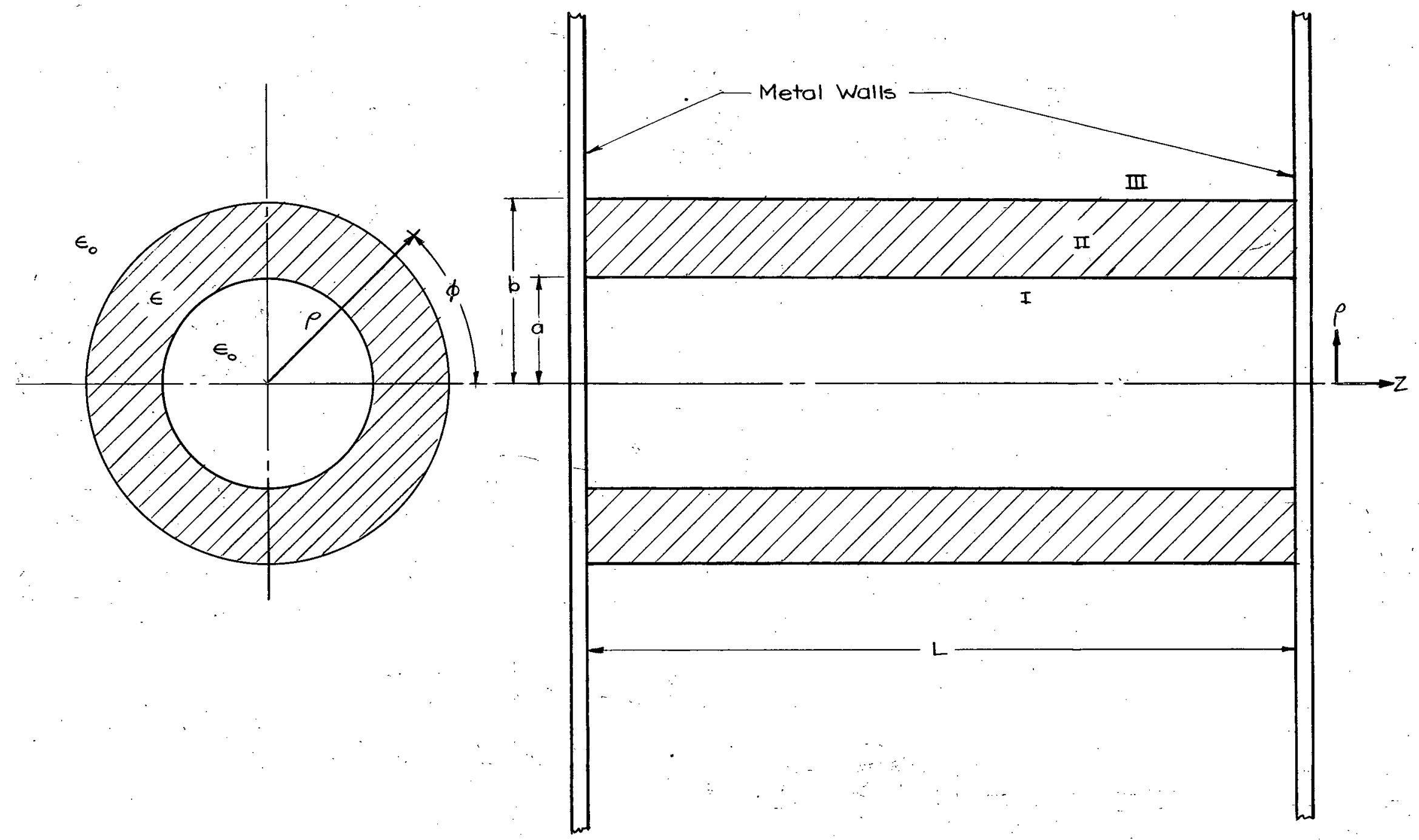

FIGURE 18 SLOW-WAVE DIELECTRIC HARMODOTRON 
of the megavolt electronics concept. The paper has been submitted to the Professional Group on Electron Devices for possible publication in their Transactions of the Institute of Radio Engineers.

\subsubsection{Submillimeter Experiment}

Since the complete theoretical investigation of the dielectric harmodotron would not be available for several months, it was decided that an experiment for producing submillimeter waves would nonetheless be attempted, utilizing bench measurements to determine certain parametric values where possible, and extrapolating such information to the desired frequency by means of appropriate scaling factors. Quarterly Progress Report No. 5 published for this contract describes this technique, employing a scale model of a slow-wave dielectric harmodotron which is nine times the actual size of the structure for producing submillimeter waves.

The design frequency chosen for the submillimeter resonator was to be the $110^{\text {th }}$ harmonic of the rebatron modulating frequency, corresponding to a wavelength of $\lambda=0.982 \mathrm{~mm}$. The beam diameter was restricted to 0.030 inch, since the entrance and exit holes for the beam would act as circular waveguides above cutoff for the submillimeter power if the holes were larger. The inner radius of the dielectric cylinder, denoted by a, was intended to be sufficiently large to prevent electrons from the beam from impinging upon the dielectric and thereby causing charging of the material. From the design curves for $v_{p} / c=0.93$, as found in the above mentioned report, a value for the outer radius, $b$, was chosen corresponding to the mode condition of $m=2$. It was necessary to choose the value given by the second root of the characteristic equation for ease of machining and maintaining tolerances. Such a choice, however, increases. the probability of mode interference, as will be seen by observing the mode charts for this device. The length, $\ell$, of the resonant structure was determined from measurements on the scale model, which indicated a condition of optimum output with negligible mode interference. The location and dimensions of the waveguide coupling aperture were also obtained from the scale model. The design dimensions for the submillimeter slow-wave dielectric harmodotron are indicated in Fig. 19, and Fig. 20 presents the complete assembly, including a tuning mechanism which 

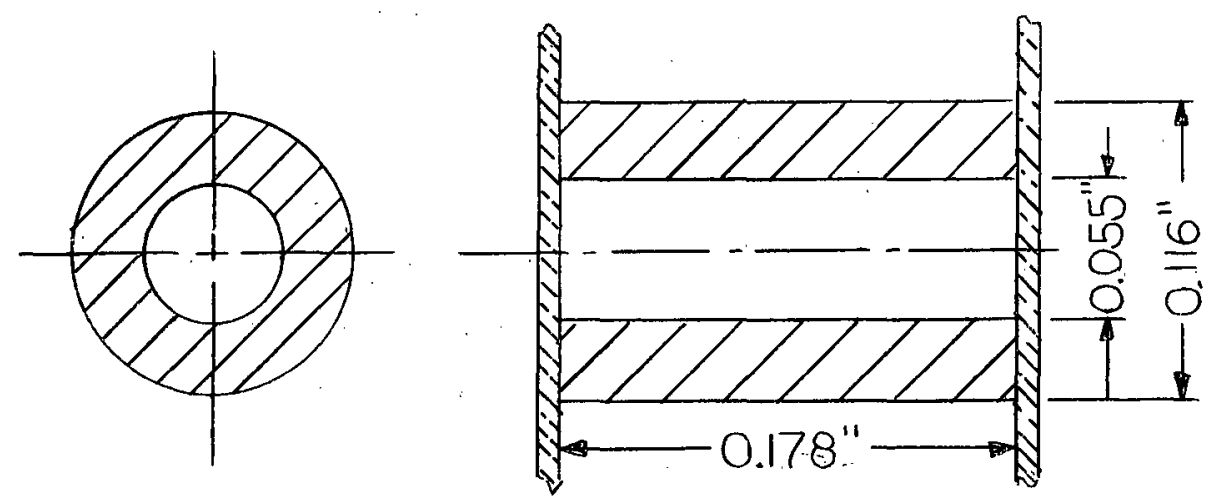

FIGURE 19 SUBMILLIMETER CAVITY

utilizes a differential screw drive. Figure 21 indicates the modes of propagation which are possible in the presently available waveguide.

The results of the experiment to date have been negative. However, as was mentioned previously, it is impossible to determine at this time whether or not this model has been designed for optimum power output at the desired frequency: In addition, it is presently impossible to know whether or not the rebatron controls have been adjusted for optimum output of the $110^{\text {th }}$ harmonic frequency, and whether the structure is resonating in the desired $\mathrm{TM}_{0,2,10}$ mode without mode degeneracy or interference. We have also been unable to evaluate our detecting devices and techniques and determine their sensitivities at these frequencies. Performance of the experiment has indicated areas in which corrective measures must be devised and employed before more significant evaluation of the slow-wave dielectric harmodotron can be made at submillimeter wavelengths.

\subsubsection{Analysis of the Slow-Wave Dielectric Harmodotron}

\subsection{Introduction}

Initial plans for the theoretical investigation of this device include the derivation of expressions for the characteristic equations and power output, together with computational work which will yield design data for the coupling structure, mode charts which include TM, TE, and hybrid modes, and power output curves. These calculations are 


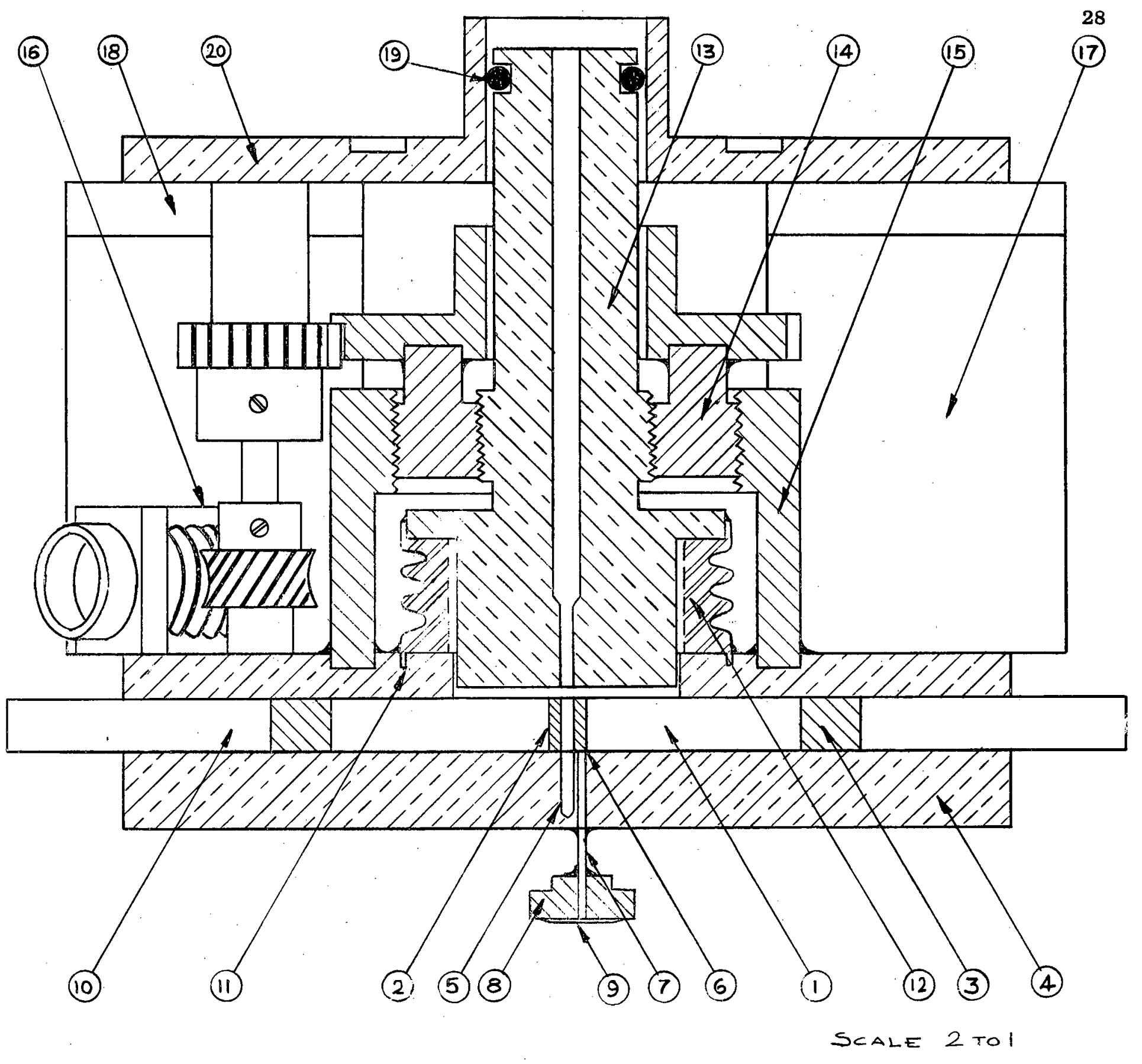

FIGURE 20 SLOW_WAVE DIELECTRIC HARMODOTRON ASSEMBLY FOR SUBMILIIMETER WAVES 
1. Dielectric Cavity

2. Dielectric Cylinder (teflon)

3. Vacuum Seal (teflon)

4. Resonator End Wall (copper)

5. Electron Beam Termination

6. Coupling Iris

7. Output Waveguide (copper)

8. Waveguide Flange (brass)

9. Waveguide Pressure Seal (mica)

10. Cavity Spacers (bakelite)

11. Resonator End Wa11 (copper)

12. Bellows (phosphor bronze)

13. Tuning Plunger (copper)

14. Differential Screw Collar (brass)

15. Tuner Base (brass)

16. Gear Drive Mechanism for Differential Screw

17. Spacer Bar (aluminum)

18. Spacer Insulator (bakelite)

19. 0-ring Vacuum Seal (rubber)

20. Flange for Rebatron Attachment (copper) 


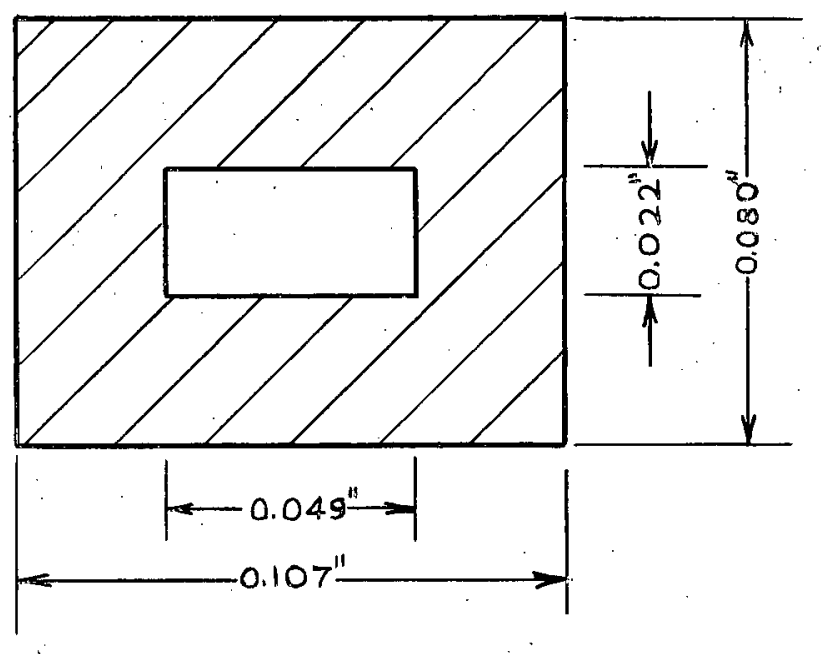

Section View: Output Waveguide

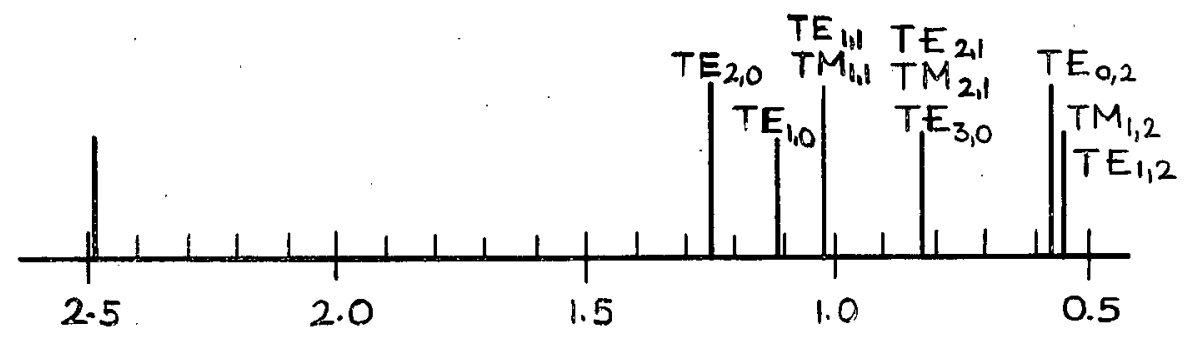

Free Space Wavelength, $\lambda$-Millimeter 
to be performed for several values of the more significant parameters, thereby affording ingight into the general behaviour of this resonant structure over its range of operation.

Quarterly Progress Report No. 5 presented graphical plots of the characteristic equation for TM modes, together with design data for the slow-wave dielectric harmodotron as derived therefrom. The following material includes several TM mode charts which display the manner in which mode interference is affected by several parameters, and presents power calculations for several cases.

\section{2 .2 .4 .2 TM omn Mode Charts}

The electron beam which passes through the slow-wave dielectric harmodotron is expected to be a symmetrical source which, in turn, excites a circularly symmetrical field within the resonator. It can be shown that only the TM and TE modes exist in the symmetrical fields of this structure. Consequently, only the TM modes are of interest in describing the interaction of the beam with the resonant fields of the coupling device, the TE modes not having an axial component of electric field.

The mode charts consist of plots of $b \lambda_{0}$ versus $b / L$. Admissible values for $b \lambda_{0}$ are taken from the design curves, and the mode configurations computed for combinations of the following parametric values:

$$
\begin{aligned}
\frac{\epsilon}{G_{0}} & =2.08 \\
\mathrm{v}_{\mathrm{p}} / \mathrm{c} & =0.80,0.88,0.93,0.97,1,00 \\
\mathrm{~m} & =1,2,3 \\
\mathrm{a} / \mathrm{b} & =0.2,0.5,0.8 \\
\mathrm{n} & =1,2,3,4,5,10,15 .
\end{aligned}
$$

The length, $\mathrm{L}$, of the resonant structure is given by

$$
L=\frac{n}{2} \frac{\mathrm{v}}{\mathrm{c}} \lambda_{0}
$$

Plotting the above information to a common scale results in the graphical 
presentations of Figs. $22 ; 23$, and 24 . It is apparent that higher values for the ratio $a / b$ indicate a diminishing in the mode interference problem. Figure 23 includes an indication of the dependence of the mode curves on the parameter $\mathrm{v}_{\mathrm{p}} / \mathrm{c}$.

\section{2,2,4,3 Power Calculations}

The power delivered by the resonant cavity to a matched waveguide output is given by

$$
P_{\text {load }}=\frac{\left|\int_{\text {vol }} \overrightarrow{\mathrm{J}} \cdot \overline{\mathrm{E}}_{\text {sol }} \mathrm{dV}\right|^{2}}{16 \mathrm{P}_{\text {lost }}}
$$

where, as shown in Quarterly Progress. Report No. 4,

$$
\left|\int \bar{J} \cdot \bar{E}_{s o l} d V\right|^{2}=\left[\frac{E_{o} L I_{s} I_{1}\left(\gamma R_{o}\right)}{\gamma R_{o}}\right]^{2}
$$

in which

$$
\begin{aligned}
& L=\text { length of the cavity } \\
& I_{\mathrm{s}_{1}}=\pi_{\mathrm{o}}^{2} \mathrm{~J}_{\mathrm{s}} \\
& R_{0}=\text { beam radius } \\
& \mathrm{J}_{\mathrm{S}}=\mathrm{s}^{\text {th }} \text { harmonic component of the electron beam current density } \\
& \gamma=2 \pi / \lambda_{0} \sqrt{\left(c / v_{p}\right)^{2}-1} \\
& \lambda_{0}=\text { free space wavelength } \\
& v_{p}=\text { phase velocity of the forward traveling wave of the resonant } \\
& c=\text { velocity of the electromagnetic propagation in vacuum } \\
& I_{1}\left(y R_{0}\right)=\text { modified Bessel function of the first kind, first order. }
\end{aligned}
$$




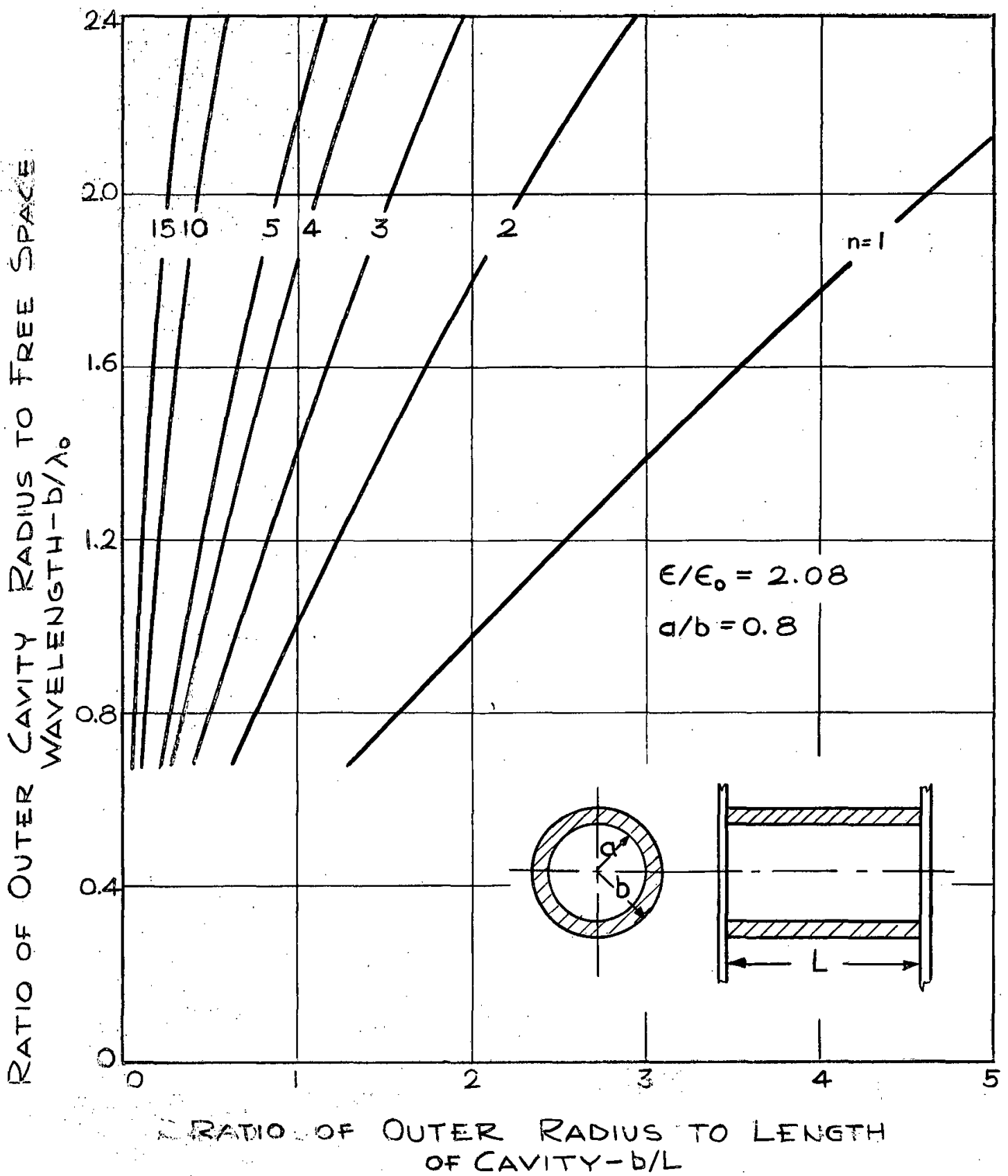

FIGURE $22 \mathrm{TM}_{\text {omn }}$ MODES FOR $\mathrm{a} / \mathrm{b}=0.3$ 


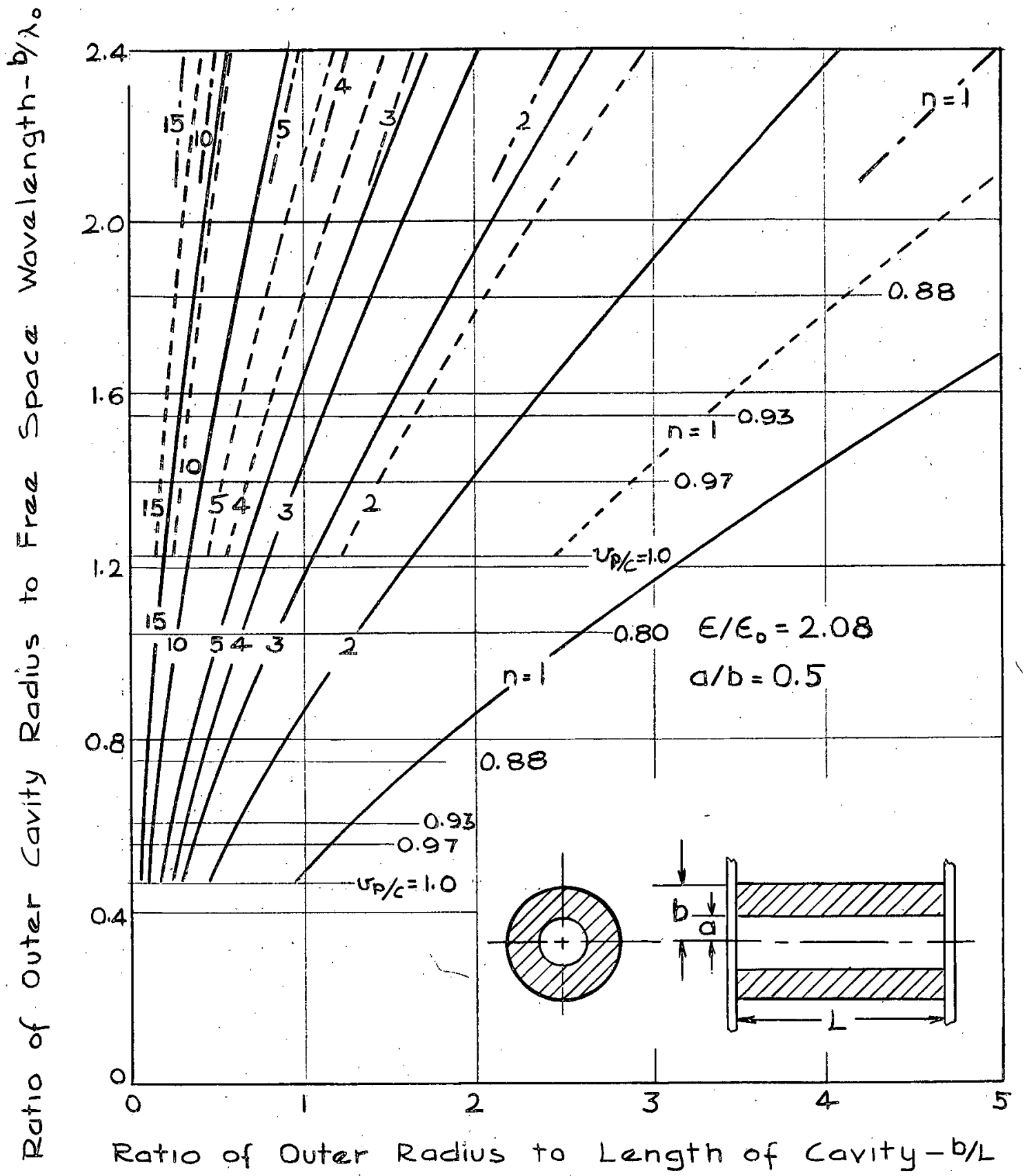

FIGURE 23 TM OMn MODES FOR $\mathrm{a} / \mathrm{b}=0.5$ 


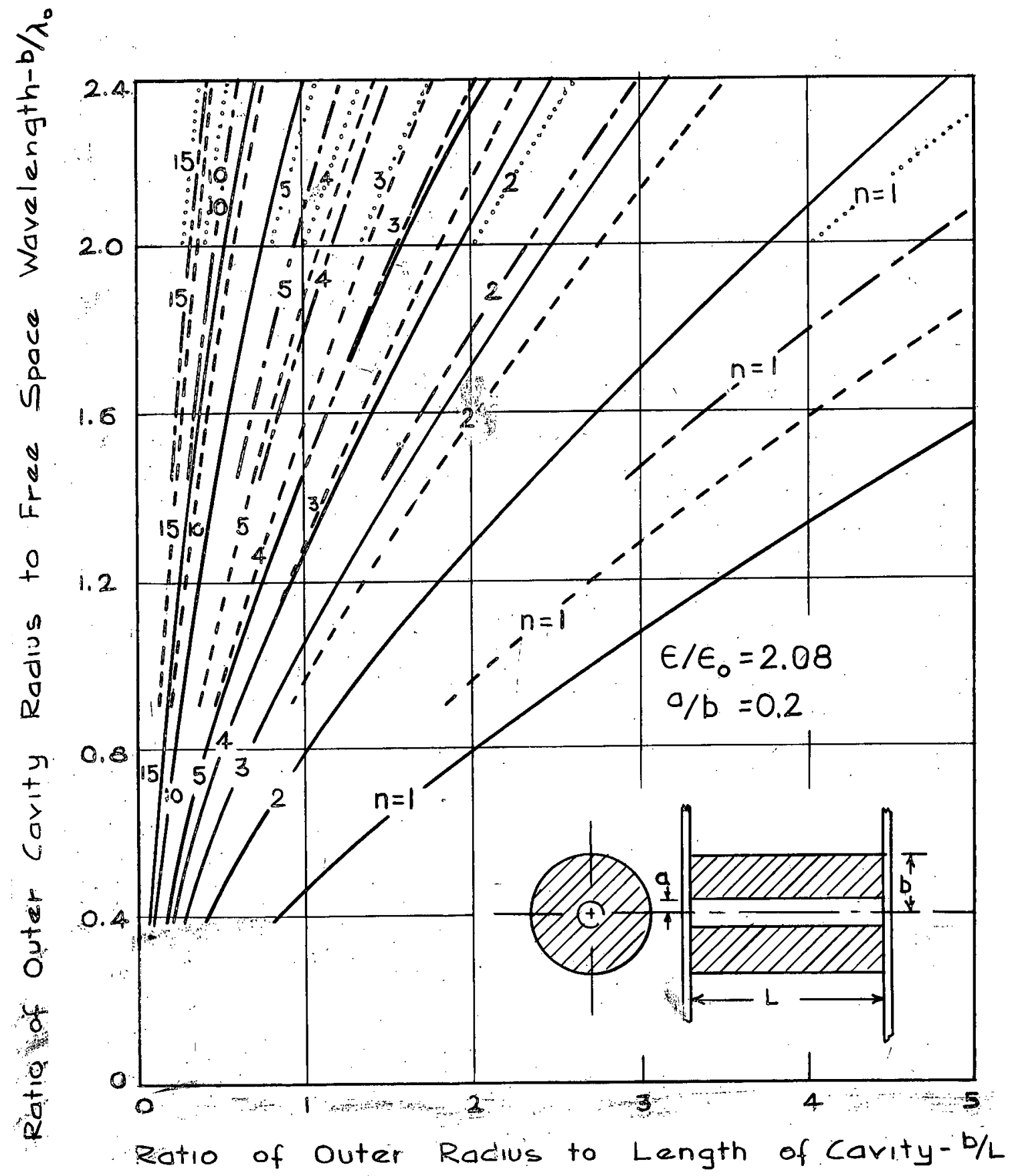

FIGURE 24 TM $_{\text {OMn }}$ MODES FOR $\mathrm{a} / \mathrm{b}=0.2$ 


$$
\begin{aligned}
& \left.\mathrm{P}_{\text {dielectric }}=\frac{\pi \sigma L \lambda_{0}^{2}}{4} \sum^{2} \frac{\rho}{\lambda_{0}}\right)^{2}\left\{\left[\mathrm{~B} J_{0}\left(F^{\prime} \frac{\rho}{\lambda_{0}}\right)+C N_{0}\left(\Gamma^{\prime} \frac{\rho}{\lambda_{0}}\right)\right]^{2}\right.
\end{aligned}
$$

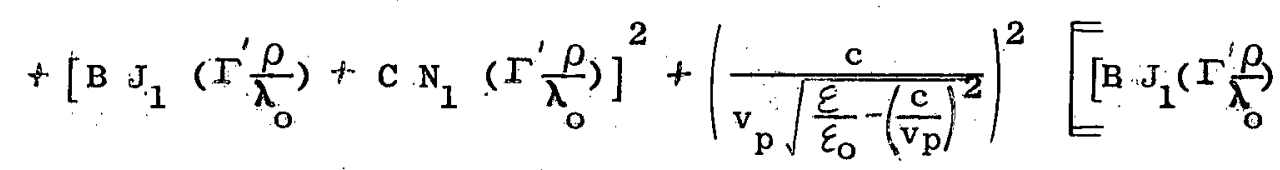

$$
\begin{aligned}
& \left.+\mathrm{C} \mathrm{N}\left(\Gamma_{1}^{\prime} \frac{\rho}{\lambda_{0}}\right)\right]^{2}-\left[\mathrm{B} \mathrm{J}_{\mathrm{o}}\left(\Gamma^{\prime} \frac{\rho}{\lambda_{\mathrm{o}}}\right)+\mathrm{C} \mathrm{N}\left(\Gamma_{0}^{\prime} \frac{\rho}{\lambda_{\mathrm{o}}}\right)\right]\left[\mathrm{B} \mathrm{J}_{2}\left(\Gamma^{\prime} \frac{\rho}{\lambda_{\mathrm{o}}}\right)\right. \\
& \left.+\cos _{2}\left(\Gamma^{\prime} \frac{\rho}{\lambda_{0}}\right)\right] \sum_{\exists a} \prod_{a}^{b / \lambda_{0}}
\end{aligned}
$$

where

$$
F=\frac{1}{\lambda_{0}} \Gamma^{\prime}=\frac{2 \pi}{\lambda_{0}} \sqrt{\frac{\varepsilon}{\varepsilon_{0}}-\left(\frac{c}{v_{p}}\right)^{2}} .
$$

The final expression for the power lost in the walls, before substituting the limits of integration, is given by

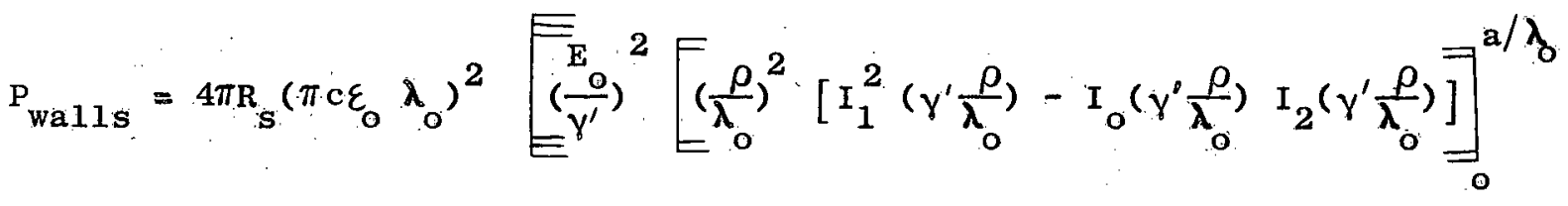

$$
\begin{aligned}
& +\left(\frac{\varepsilon}{\varepsilon_{0}} \frac{1}{\Gamma^{i}}\right)^{2}\left[( \frac { \rho } { \lambda _ { 0 } } ) ^ { 2 } \left\{\left[\mathrm{BJ}_{1}\left(\Gamma^{\prime} \frac{\rho}{\lambda_{0}}\right)+\mathrm{CN}_{1}\left(\Gamma^{\prime} \frac{\rho}{\lambda_{0}}\right]^{2}-\left[\mathrm{BJ}_{0}\left(\Gamma^{\prime} \frac{\rho}{\lambda_{0}}\right)+\mathrm{CN}_{0}\left(\Gamma^{\prime} \frac{\rho}{\lambda_{0}}\right)\right]\right.\right.\right. \\
& \left.\left.\left[\mathrm{BJ}_{2}\left(\Gamma^{\prime} \frac{\rho}{\lambda_{\mathrm{o}}}\right)+\mathrm{CN}_{2}\left(\Gamma^{\prime} \frac{\rho}{\lambda_{0}}\right)\right]\right\}\right]_{\mathrm{a}} / \lambda_{\mathrm{o}} \\
& \left.+\left(\frac{\underline{p}}{\gamma^{\prime}}\right)^{2}\left[{ }_{=\lambda_{0}}\right)^{2}\left[\mathrm{~K}_{0}\left(\gamma^{\prime} \frac{\rho}{\lambda_{0}}\right) \mathrm{K}_{2}\left(\gamma^{\prime} \frac{\rho}{\lambda_{0}}\right)-\mathrm{K}_{1}^{2}\left(\gamma^{\prime} \frac{\rho}{\lambda_{0}}\right)\right]\right]_{b / \lambda_{0}}^{\infty} \exists
\end{aligned}
$$

where

$$
R_{s}=\text { surface resistivity of the metal walls }
$$


and

$$
\begin{aligned}
& B=\frac{\pi}{2} \operatorname{Ta} E_{0}\left[\frac{\varepsilon}{\varepsilon} \frac{\Gamma}{\gamma} N_{0}\left(F^{\prime} \frac{a}{\lambda_{0}}\right) I_{1}\left(\gamma^{\prime} \frac{a}{\lambda_{0}}\right)-I_{0}\left(\gamma^{\prime} \frac{a}{\lambda_{0}}\right) N_{1}\left(F^{\prime} \frac{a}{\lambda_{0}}\right)\right] \\
& C=-\frac{\pi}{2} \operatorname{Fa} E_{0}\left[\frac{\varepsilon_{0}}{\varepsilon} \frac{\Gamma}{\gamma} J_{0}\left(\Gamma^{\prime a} \frac{a}{\lambda_{0}}\right) I_{1}\left(\gamma^{\prime} \frac{a}{\lambda_{0}}\right)-I_{0}\left(\gamma^{\prime} \frac{a}{\lambda_{0}}\right) J_{1}\left(I^{\prime} \frac{a}{\lambda_{0}}\right)\right] \\
& \mathrm{D}=-\frac{\pi}{2} \Gamma_{\mathrm{a}} \frac{\mathrm{E}_{\mathrm{o}}}{\mathrm{K}_{\mathrm{o}}\left(\gamma^{\prime} \frac{\mathrm{b}}{\lambda_{0}}\right)}\left\{\frac{\varepsilon_{0}}{\varepsilon} \frac{\Gamma}{\gamma} I_{1}\left(\gamma^{\prime} \frac{\mathrm{a}}{\lambda_{0}}\right)\left[\mathrm{N}_{0}\left(\Gamma^{\prime} \frac{\mathrm{b}}{\lambda_{0}}\right) J_{0}\left(\Gamma^{\prime} \frac{\mathrm{a}}{\lambda_{0}}\right)-\mathrm{N}_{0}\left(\Gamma^{\prime} \frac{\mathrm{a}}{\lambda_{0}}\right) J_{0}\left(\Gamma^{\prime} \frac{\mathrm{b}}{\lambda_{0}}\right)\right]\right. \\
& \left.+I_{0}\left(\gamma^{\prime} \frac{a}{\lambda_{0}}\right)\left[J_{0}\left(F^{\prime} \frac{b}{\lambda_{0}}\right) N_{1}\left(F^{\prime} \frac{a}{\lambda_{0}}\right)-J_{1}\left(F^{\prime} \frac{a}{\lambda_{0}}\right) N_{0}\left(T^{\prime} \frac{b}{\lambda_{0}}\right)\right]\right\}
\end{aligned}
$$

and where

$$
\gamma=\frac{1}{\lambda_{0}} \gamma^{\prime}=\frac{2 \pi}{\lambda_{0}} \sqrt{\left(\frac{c}{v_{p}}\right)^{2}-1} .
$$

The values for $a / \lambda_{0}$ and $b / \lambda_{0}$ are necessarily taken from the design curves if resonance is to occur in the desired TM mode.

If the expressions appearing within the triple brackets, are denoted by $\mathrm{P}^{\prime}$ dielectric and $\mathrm{P}_{\text {walls, }}^{\prime}$ respectively, then the exact expression for the power delivered to a matched output of the slow-wave dielectric harmodotron is

$P_{\text {load }}=\frac{\left[n R_{o} J_{s} \lambda_{o}\left(v_{p} / c\right) I_{1}\left(y R_{o}\right)\right]^{2}}{64\left(\gamma^{\prime}\right)^{2} \varepsilon_{o} c\left[\frac{\varepsilon}{\varepsilon_{0}} \frac{n}{4} \frac{v_{p}}{c} \tan \delta P_{\text {dielectric }}^{\prime}+4 \pi \varepsilon_{o} \text { ck } \sqrt{f} P_{\text {walls }}^{\prime}\right]}$

since

$$
\begin{aligned}
& \sigma=2 \pi \mathrm{f} \varepsilon \tan \delta \text { mhos } / \mathrm{m} . \\
& \mathbf{R}_{\mathrm{s}}=\mathrm{k} \sqrt{\mathrm{f}} \text { ohms. }
\end{aligned}
$$

Quarterly Progress Report No 4 describes the results of an 
experiment which was performed at a wavelength of $9 \mathrm{~mm}\left(12^{\text {th }}\right.$ beam harmonic) using the slow-wave dielectric harmodotron. The following conditions existed:

$$
\begin{aligned}
\mathrm{TM}_{0}, 1,14 \text { mode } \\
\mathrm{v}_{\mathrm{p}} / \mathrm{c}=0.93 \\
\frac{\varepsilon}{\varepsilon_{0}}=2.08 \quad \text { tan } \delta=6 . \times 10^{-4} \text { (teflon) } \\
\mathrm{k}=2.61 \times 10^{-7} \text { ohms (copper) } \\
f=33.30 \mathrm{kmc} / \mathrm{s} \\
\mathrm{R}_{\mathrm{O}}=0.5 \mathrm{~mm} . \\
\mathrm{a}=0.080^{\prime \prime} \\
\mathrm{b}=0.205^{\prime \prime} \\
\mathrm{L}=2.301^{\prime \prime} \\
I_{\mathrm{O}}=4.5 \times 10^{-3} \text { amp. }
\end{aligned}
$$

The output power actually measured was 160 milliwatts and the expected power output determined from bench measurements was $330 \mathrm{mil1i-}$ watts. This latter value was calculated from

$$
P_{\text {load }}=\frac{\left|\int_{\text {vol }} \bar{J} \cdot \bar{E}_{\text {sol }} d V\right|^{2}}{16 P_{\text {lost }}} \text { watts }
$$

where

$$
P_{10 s t}=\frac{\varepsilon_{0} \pi f^{2} E_{0}^{2}}{2 Q} \lim _{\Delta V \rightarrow 0}\left(\frac{\Delta V}{\Delta f}\right)
$$

and the bench measurements yielded

$$
\begin{aligned}
& Q=4000 \\
& \lim _{\Delta v \rightarrow 0}\left(\frac{\Delta f}{\Delta v}\right)=9.1 \times 10^{9} \mathrm{cycles} / \mathrm{cm}^{3} .
\end{aligned}
$$


The purely theoretical value for the output power of the slow-wave dielectric harmodotron at this frequency was computed to be 455 milliwatts. Tabulation of these results provides an immediate appraisal of the agreement between theory and experiment.

$$
\begin{aligned}
& P_{\text {load }}(\text { theoretical) }=455 \mathrm{mw} . \\
& \mathrm{P}_{\text {load }}(\text { empirical) }=330 \mathrm{mw} \\
& \mathrm{P}_{\text {load }}(\text { experimental) }=160 \mathrm{mw} \\
& \frac{P_{\text {load }}(\text { experimental) }}{P_{\text {load }}(\text { theoretical) }}=35.2 \% \\
& \frac{P_{\text {load }}(\text { experimental) }}{P_{\text {load }} \text { (empirical) }}=48.5 \% \\
& \frac{P_{\text {load }}(\text { empirical) }}{P_{\text {load }}(\text { theoretical) }}=72.5 \%
\end{aligned}
$$

The agreement between theory and experiment is most satisfying since the experimental power value has not been corrected for attenuation due to propagation in the output waveguide from the coupling aperture to the crystal detector. Then, too, the actual twelfth harmonic current component is not exactly known, and some error due to inaccuracy of the bolometer and mount used for calibration of the crystal detector is undoubtedly involved.

Figure 25 presents one set of power curves for this coupling device at $\lambda_{0}=9 \mathrm{~mm}_{3}$ and indicates the value of the theoretical power output expected for the experiment. 




FIGURE 25 THEORETICAL POWER CURVES FOR THE SLOW-WAVE DIFIECTRIC HARMODOTRON FOR $\lambda_{\mathrm{o}}=9 \mathrm{~mm}$. 


\subsection{Detecting and Measuring Techniques}

\subsubsection{Purpose}

The objective of this research is to develop suitable detectors and power and frequency measuring instruments for evaluating the characteristics of the radiation produced by any of the beam coupling schemes and for using the radiation as a diagnostic tool in research.

\subsubsection{Millimeter Wave Techniques - A.W. Swago}

\subsubsection{Crysta1 Multipliers}

During the past interval, primary attention was given to further modifications of in-guide crystal harmonic multipliers and detectors, in an effort to obtain greater reliability and less frequency sensitivity.

The report for the previous interval described a crossed-guide singleplane multiplier which had been developed in an attempt to reduce both the complexity of assembly and the electrical coupling difficulties. While this device showed some improvement over the previous two-plane system it did not give the degree of frequency independence wished for. Further, the geometry in the whisker region is that of a four-port cavity; permitting possible harmonic power flow through any or all of the ports, as determined by the tuning of the remainder of the system. (In checking this; it was found that, for a particular crossed-guide multiplier, it was possible to so tune the klystron driver and the tunable shorts as to obtain harmonic power in either the fundamental guide or the harmonic guide, but not simul taneously in both:

Also, for some time; intultion has led us to belleve that some of the frequency sensitivity in previous multipliers tested has been due to a harmonic current standing wave distribution which we feel exists along the whisker. If, for example, the distribution were to be such that two symmetrical, but out-of-phase, current loops existed in the region of the whisker bounded by the guide, it would be expected that no net power would be radiated down the guide, while an assymetrical distribution would produce radiation, In addition, the effect of the whisker-crystal junction as a terminating device on the current distribution is unknown. Since it is impossible to physically probe the field along the whisker surface, one can only make a guess as to the distribution. For a given junction however, 
the distribution near the crystal end of the whisker should remain the same if the whisker length is not apprectably changed. Hence, if the whisker were to be effectively moved perpendicular to the guide, the distribution might then be altered to give an assymetrical pattern in the guide region, with resulting radiation. No easy method of multiplier construction which would permit stuch adjustment continuously without introducing other problems has been suggested.

The latest mutiplier modification evolved during the past interval was the result of both considerations. It consists merely of a piece of fundamental guide, tapered down in the narrow dimension. The crystalWhisker combination is mounted in the center of the narrowed section. A taper section, which makes the transition from fundamental guide to harmonic guide dimensions, serves as a good reactive termination for the fundamental system, while permitting transfex of harmonic power. To permit "Iine-stretching" and consequent placement of maximum E-field at the whisker location, a dielectric phase shifter is used. This consists of a conventional flap attenuator in which the resistance card has been replaced by a similarly shaped strip of teflon. The overail system is sketched in Fig。26.
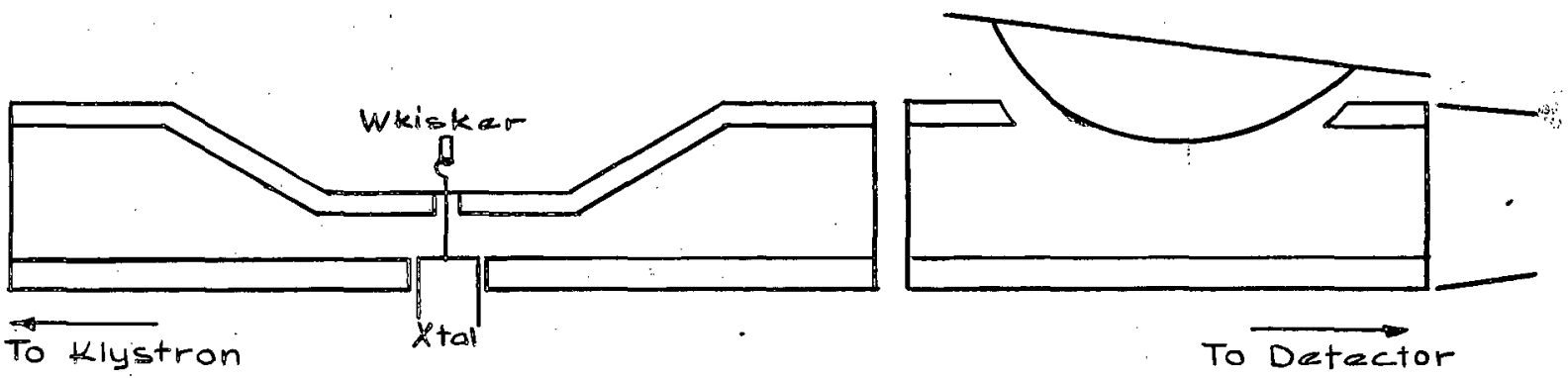

As a doubler, using a QK 288 klystron tube as driver, there seemed to be essentially no frequency regions (over the range of the klystron) in which second harmonic power was not produced. To check the effects of: necking down the guide, another unit, using a straight section of guide but otherwise constructed as much like the necked-down unit as possible, 
was tested. Second harmonic power was not observed over most of the range of the QK 288. Since the relative guide dimensions of the two sections are roughly on the order of $2: 1$, it was felt that the assumptions regarding current distribution on the whisker were fairly well substantiated.

During the last few weeks of the interval, just before the vacation period, two VX5023T/R9521 klystron tubes, manufactured by E.M.I. Electronics, Ltd, of Middlesex, England, were obtained. These $8 \mathrm{~mm}$ tubes deliver approximately $60 \mathrm{mw}$ power over some portions of their operating range, and will thus be capable of driving the multiplier to a greater extent than the QK 288 tubes previously used. Two other sections of different necked-down dimensions have been electroformed and will be machined and assembled during the next interval. It is expected that during this interval, a final design will be selected for use as a source, after which further investigations of crystal harmonic generators as such will be suspended.

The various types of multipliers described are shown in Fig. 10 .

\subsubsection{Detectors for $2 \mathrm{~mm}$ and $1 \mathrm{~mm}$.}

Further modifications of the in-guide detectors have been made during this interval. Differential screw drives giving advancement rates of 0.00119 in turn have been made and incorporated into the latest versions. A rough (56 turns/inch) preliminary positioning adjustment not only permits initial placement of the whisker to within the differential screw operating range, but also acts as a self-jigging arrangement for inserting the whisker through the small hole of the guide. The latter feature is also the result of interchanging the whisker and crystal positions; so that the whisker mount, forming part of the ground system, 'is driven toward the insulated crystal, connected to the center conductor of the cable to the amplifier system. Thts removes the necessity of insulating the whisker from the guide, which had been troublesome in past models. Since stiffness of the cable used with BNC connectors causes some motion of the crystal when the cable is disturbed, the mount will be modified to use SM connectors with very small coaxial cable. Such a detector appears in the lower left corner of Fig. 10. 
Work on coherent circuits initiated previously will be resumed during the next interval. A low-noise, narrow-band, modified type $P$ amplifier has been obtained from a commercial source but has not yet been incorporated into the detection system.

A miniaturized version of the 1N53 cartridge, as modified for use with our detectors, has been designed in collaboration with Mr. Stafford, and negotiations to obtain and mount the necessary crystal dicings have been initiated. While the in-guide detectors are suitable for laboratory bench use, where the unit will be disturbed as little as possible, they are not considered sufficiently rugged for uses in which the detector unit must be connected to large pieces of heavy equipment more liable to accidental shocks, or for field use. It is expected that construction of necessary jigs and procurement of parts will not permit assembly of any such units before the end of the next interval. 


\section{DISTRIBUTION .LIST FOR ALL REPORTS}

Contract AT- $(11-1)-392$

One copy each unless otherwise indicated

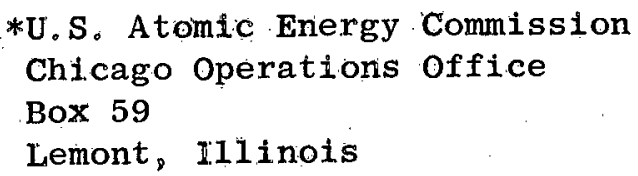

Attn: Mr. L。A. Redecke 6 copies

Dr。Arthur E。 Ruark

Controlled Thermonuclear Branch

Division of Research

U.S. Atomic Energy Commission

Washington 25 , D.C.

Dr。Hilliard Roderick

U.S. Atomíc Energy Commission Controlled Thermonuclear Branch

Division of Research

Washington 25 , D. C

Dr. James Tuck

Los Alamos Sctentific Laboratory

P.O。 Box 1663

Los Al amos. N.M.

Dr. Mark A. Heald

Project Matterhorn

$P_{0}$ O B Box 451

James Forrestal Research Center

Princeton University

Princeton, $N_{\text {。 }}$.

Dr. Charles Bo Wharton

University of California

Radiation Laboratory.

Livermore, California

Br. Donald Slager

Los Alamos Scientific Laboratory

P.O. Box 1663

Los Alamos, NoM.

Dr。P. Bell

Oak Ridge National Laboratory

Oak Ridge, Tennessee

*Contractor
Dr. Donald Kerr

Dept. of Physics

Johns Hopkins University

Baltimore 18, Md.

Miss Mary $H_{0}$ Newman

Catalog Operations Section

Cataloging Branch

United States Atomic Energy Commission

Technical Information Service

Post office Box 62

Oak Ridge, Tennessee 10 plus 1 repro.

Dr. Harry Dreiser

Los Alamos Scientific Laboratory

P. 0 . Box 1663

Los Alamos; New Mexico

Commander

Wright Air Development Center

Wright-Patterson $A F B$, ohio

Attn: :WCLRW-5

Armed Services Technical Information

Knott Bullding Agency

4 th and Main street

Dayton 2, Ohio

Attn: DSC-SA 10 plus 1 repro.

Commander

Wright Air Development Center

Wright-Patterson AFB, Ohio

Attn: WCOSI (for further processing to Rand Corp.) 2 copies

Chief, Bureau of Aeronautics

Department of the Navy

Washington $25, D_{0} C$.

Attn: Electronics Division

Bureau of Aeronautics General

Representative, Central District

Wright-Patterson AFB, Ohio

Attn: Electronics Division 
Chief, Bureau of Ships

Department of the Navy

Washington $25, D, C$.

Attn: Code 816

Director

Naval Research Laboratories

Washington $25, D_{0} C$,

Attn: Code 2021

office of the Chief Signal officer Washington 25 , D. C.

Attn: Engineering \& Technical Div.

Commander

Signal Corps Engineering Laboratory

Fort Monmouth, New Jersey

Attn: SIG-EL-RDR

Commander

Air Force Cambridge Research Center

Air Research \& Development Command

Laurence G. Hanscom Field

Bedford, Massachusetts

Attn: CRTOTT-2

Commander

Rome Air Development Center

Griffiss Air Force Base

Rome, New York

Attn: Research Library, RCRES-4C

Aquisitions Section

Library

National Institute of Health

Bethesda 14; Maryl and

Dr. Edward McArthur

Research Laboratory, Box 1088

Genera1 Electric Company

Schenectady, New York

The Johns Hopkins University

Operations Research office

7100 Connecticut Avenue

Chevy Chase, Maryland

Contract $\mathrm{BA} 44-109-\mathrm{QM}-266$
Dr. Theodore Moreno

Varian Associates

611 Hansen Way

palo Alto, California

Mr. Lorn Howard

E.E. Department

Michigan state University

East Lansing, Michigan

John Hewitt

Research Laboratory of Electronlics Massachusetts Institute of Technology Cambridge; Massachusetts

Mr . Edward, W. Herold

Director, Radio Tube Research Lab.

RCA Laboratories Division

Princeton, New Jersey

John M. Richardson

National Bureau of Standards

Boulder, Colorado

Dr. H.R. Johnson

Research and Development Laboratory

Hughes Aircraft Company

Culver City, California

Dr。W.D. McBee

IA40

Sperry Gyroscope Company

Great Neck, L. I。, New York

Commanding General

Redstone Arsena1

Huntsvilie, Alabama

Attn: Technical Library

Dr. Arthur Kip

Department of Physics

University of California

Berkeley 4, California

Massachusetts Institute of Technology

Cambridge, Massachusetts

Attn: Prof. Richard Lord

Director, Spectroscopy Lab. 


\section{DISTR IBUTION LIST (CONTINUED)}

Dr. Paul J. Ovrebo

957. Ridgeview. Road

Dayton 9, Ohio

Bel1 Telephone Laboratories

Homde1, New .Jersey

Attn: W.M. Sharpless

Contract Nonr-687 (00)

Dr. Gerhard E. Weibel

Microwave Tube Section

Physical Electronics Branch

Sylvania Electric Products, Inc.

Bayside, $\mathbf{L}_{0} \mathbf{I}_{o}$, New York

Applied Electronics Laboratory

Stanford University

Stanford, California

Attn: Dr。 Glen Wade

Dr. T.S. England

British Joint Services Mission

P. $\mathrm{O}_{\text {, }}$ Box 680

Benjamin Franklin Station

Washington, $\mathbf{D}_{0} \mathbf{C}$.

(Forward to Malvern, England)

Commanding officer

$U_{0} S_{\text {: Naval Ordnance Laboratory }}$

Corona, California

Attn: Mr。A.J. Cussen, via Library

Dr。Walter Dyke

Linfield Research Institute

McMinnvilie, Oregon

Dr. Irving Kaufman

Ramo-Wool ridge Company

Electronic Research Laboratory

Los Angeles, California

Dr。 Murray D. Sirkis

Rutgers University

Electrical Engineering Department

New Brunswick, NoJ.
Dr. Harold J. Hersh

Chief, Microwave Tubes Branch, REM

U.S. Army Signal Engineering Laboratories

Fort Monmouth, N, J。

Mr。G.S. Heller

Lincoln Laboratory

Massachusetts Institute of Technology

Box 73

Lexington, Massachusetts

Microwave Laboratopy

W.W. Hansen Laboratories of Physics

Stanford University

stanford, California

Dr. Richard E. Hillger, Head

Communication and Electronic

System Section

Advance Industries, Inc.

640 Memorial Drive

Cambridge 39, Massachusetts

Dr. E.C. Jordan, Head

Department of Electrical Engineering

University of Illinois

Urbana, Illinois

Engineering Library

Civil Engineering Hall

University of Illinois

Urbana, I11inois

3 copies

Dr. Tykociner

Electrical Engineering Research Lab.

Jniversity of Illinois

Urbana, Illinois

Prof W.E. Miller

Electrical Engineering Building

University of Ililnois

Urbana, Illinois

Prof. E.C. McClintock

109 Civil Engineering Hall

University of Illinois

Urbana, IIIInois 


\section{DISTRIBUTION LIST (CONTINUED)}

Dr。 W.L. Everitt, Dean School of Engineering University of Illinois Urbana ${ }_{0}$ Illinois

2 copies

Project staff

C/O. Dr. P. Coleman, Director

15 copies 